\title{
Characterization of the bio-optical anomaly and diurnal variability of particulate matter, as seen from scattering and backscattering coefficients, in ultra-oligotrophic eddies of the Mediterranean Sea
}

\author{
H. Loise ${ }^{1}$, V. Vantrepotte ${ }^{1}$, K. Norkvist ${ }^{1}$, X. Mériaux ${ }^{1}$, M. Kheireddine ${ }^{2}$, J. Ras ${ }^{2}$, M. Pujo-Pay ${ }^{3,4}$, Y. Combet ${ }^{5}$, \\ K. Leblanc ${ }^{5}$, G. Dall'Olmo ${ }^{6}$, R. Mauriac ${ }^{7}$, D. Dessailly ${ }^{1}$, and T. Moutin ${ }^{6}$ \\ ${ }^{1}$ INSU-CNRS, UMR 8187, LOG, Laboratoire d'Océanologie et des Géosciences, Université Lille Nord de France, \\ ULCO, 32 avenue Foch, 62930 Wimereux, France \\ ${ }^{2}$ INSU-CNRS, LOV, Lab. d'Océanographie de Villefranche, UMR 7093, Université Paris VI, Villefranche sur mer, France \\ ${ }^{3}$ INSU-CNRS, UMR 7621, LOMIC, Laboratoire d'Océanographie Microbienne, Observatoire Océanologique, \\ 66650 Banyuls/mer, France \\ ${ }^{4}$ UPMC Univ Paris 06, UMR 7621, LOMIC, Laboratoire d'Océanographie Microbienne, Observatoire Océanologique, \\ 66650 Banyuls/mer, France \\ ${ }^{5}$ INSU-CNRS, UMR 6535, LOPB, Laboratoire d'Océanographie Physique et Biogéochimique, Université de la Méditerranée, \\ Centre d'Océanologie de Marseille, Campus de Luminy Case 901, 13288 Marseille cedex 9, France \\ ${ }^{6}$ Plymouth Marine Laboratory, Prospect Place, The Hoe, Plymouth, PL1 3DH, UK \\ ${ }^{7}$ INSU-CNRS, UMR 6535, LOPB, Laboratoire d'Océanographie physique et biogéochimique Université de la Méditerranée, \\ Centre d'Océanologie de Marseille, Campus de Luminy Case 901, 13288 Marseille cedex 9, France
}

Received: 31 July 2011 - Published in Biogeosciences Discuss.: 8 August 2011

Revised: 27 October 2011 - Accepted: 28 October 2011 - Published: 14 November 2011

\begin{abstract}
The variability of inherent optical properties is investigated in the ultra-oligotrophic waters of the Mediterranean Sea sampled during the BOUM experiment performed during early summer 2008. Bio-optical relationships found for ultra-oligotrophic waters of the three anticyclonic gyres sampled significantly depart from the mean standard relationships provided for the global ocean, confirming the peculiar character of these Mediterranean waters. These optical anomalies are diversely related to the specific biological and environmental conditions occurring in the studied ecosystem. Specifically, the surface specific phytoplankton absorption coefficient exhibits values lower than those expected from the general relationships mainly in relation with a high contribution of relatively large sized phytoplankton. Conversely, the particulate backscattering coefficient, $b_{\mathrm{bp}}$, values are much higher than the mean standard values for a given chlorophyll- $a$ concentration, TChl- $a$. This feature can presumably be related to the relevant influence of highly refractive submicrometer particles of Saharan origin in the surface layer of the water column. The present measurements
\end{abstract}

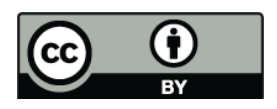

Correspondence to: $\mathrm{H}$. Loisel (hubert.loisel@univ-littoral.fr) also show that the Mediterranean Sea is greener than TChl$a$ alone indicates, as already stressed in previous studies. This color anomaly is partly explained by the estimated colored dissolved organic matter and submicrometer particles absorption coefficients, and to a greater extent by the high $b_{\text {bp }} /$ TChl- $a$ values assuming that these particles backscatter light similarly in the green and blue parts of the visible spectrum. The diel variation of both the particulate matter attenuation and backscattering coefficients were also investigated specifically. Despite some differences in the timing and the magnitude of the daily oscillations found for these optical parameters, potential for the backscattering coefficient daily oscillation to be used, similarly to that for the attenuation coefficient, as a proxy for estimating carbon community production budget has been highlighted for the first time. This result is particularly relevant for present and future geostationary spatial ocean color missions.

\section{Introduction}

In situ and remote sensing measurements of inherent optical properties (IOPs) in natural waters provide essential information to infer biogeochemical stocks and processes at

Published by Copernicus Publications on behalf of the European Geosciences Union. 
different temporal and spatial scales (Smith and Baker, 1978; Nelson et al., 1998; Stramski et al., 1999; Oubelkheir et al., 2005; Boss et al., 2007; Vantrepotte et al., 2011). General bio-optical relationships have long been established between these IOPs and some biogeochemical parameters, such as the chlorophyll- $a$ concentration, Chl- $a$, and particulate organic carbon, POC, in open ocean waters (Gordon and Morel, 1983; Yentsch and Phinney, 1989; Bricaud et al., 1995; Oubelkheir et al., 2005; Gardner et al., 2006; Huot et al., 2008). These relationships can then be used to assess the variability of the latter biogeochemical parameters from field or remote sensing measurements. The universal (i.e. global) status of these relationships can only be stated by characterizing and understanding the variability around these averaged laws which describe the mean trends observed between the IOPs and the biogeochemical parameters concentration. At first order, the IOPs variability is driven by the concentration of the optically significant material present in the water masses. For instance, robust statistical relationships (Loisel and Morel, 1998; Bricaud et al., 1998) have been established between the particulate attenuation, $c_{\mathrm{p}}$, and absorption, $a_{\mathrm{p}}$, coefficients with Chl- $a$ over the whole trophic range (covering about three orders of magnitude). The biooptical characteristics of the particulate and dissolved matter, as well as the respective proportion between these different optically active pools, drive the natural variability observed around the averages relationships between IOPs and biogeochemical parameters. Here we examine the IOPs variability for ultra-oligotrophic waters of the Mediterranean Sea sampled in the frame of the BOUM (Biogeochemistry from the Oligotrophic to the Ultra-oligotrophic Mediterranean) cruise carried out in early summer, June-July 2008 (Moutin et al., 2011).

While numerous field measurements were acquired to established bio-optical relationships representative of the open ocean (see Morel, 2009 and references therein), in situ measurements performed in ultra oligotrophic waters (i.e. Chl- $a$ lower than about $0.05 \mathrm{mg} \mathrm{m}^{-3}$ ) are still very scarce. This is particularly true for the particulate backscattering coefficient, $b_{\mathrm{bp}}$, which has been rarely measured in oligotrophic waters. Recent bio-optical relationships (Huot et al., 2008; Bricaud et al., 2010) were however established, thanks to the large trophic gradient covered in the frame of the BIOSOPE cruise which was carried out in the eastern South Pacific Ocean (Claustre et al., 2008). Compared to the South Pacific gyre system, where ultra ologotrophic waters were sampled during BIOSOPE, the Mediterranean Sea waters and their associated bio-optical relationships can be affected by continental inputs such as rivers discharge and desert dust events. Different studies have already stressed the marginal character of this semi enclosed sea at a bio-optical point of view (Gitelson et al., 1996; D'Ortenzio et al., 2002; Claustre et al., 2002; Bricaud et al., 2002; Morel and Gentili, 2009). A higher than expected colored dissolved organic matter content, a presence of coccolithophorids, and Saharan dust events were advanced to explain the over-estimation, compared to the field values, of Chl- $a$ loads retrieved from the standard bio-optical algorithms used to process ocean color data collected from space. The first objective of the present study is to re-examine this well known, but still not fully understood, color anomaly found in ultra-oligotrophic waters of the Mediterranean Sea, with a particular focus on the particulate backscattering coefficient, $b_{\mathrm{bp}}$, which was never measured during previous studies.

Diel variation in $c_{\mathrm{p}}$ has been extensively reported in various parts of the world oceans and has been used to infer biogeochemical processes such as particles growth rates and productivity (Cullen et al., 1992; Claustre et al., 2008; Marra, 1995; Gardner et al, 1999; Oubelkheir and Sciandra, 2008; Gernez et al, 2011; Dall'Olmo et al., 2011; Walsh et al., 1995). With minima near sunrise and maxima near sun set, the $c_{\mathrm{p}}$ diel variations have been mainly attributed to variations in refractive index and size of phytoplankton cells during the photosynthetic processes (Stramski and Reynolds, 1993; Durand and Olson, 1998). Note that changes in particles (phytoplankton and heterotrophic bacteria) numerical concentration also contribute to the $c_{\mathrm{p}}$ diel cycle (Oubelkheir and Sciandra, 2008). Conversely, diurnal cycles in $b_{\text {bp }}$ have not been documented yet and represent therefore the second major objective of the present study. The characterization of the $b_{\mathrm{bp}}$ diel cycle is motivated by two major aspects. First, in the frame of the Mie scattering theory, $b_{\mathrm{bp}}$ is mostly influenced by submicrometer particles, whereas $c_{\mathrm{p}}$ is mainly driven by particles with diameters between 0.5 and $20 \mu \mathrm{m}$ (Stramski and Kieffer, 1991; Pak et al., 1988). Therefore, the comparison of the respective diel cycles of the two latter optical parameters could provide complementary information on related biogeochemical processes. Note, however, that the influence of relatively large phytoplankton cells on $b_{\mathrm{bp}}$ seems to be underestimated from Mie calculations according to recent experimental studies (Vaillancourt et al., 2004; Dall'Olmo et al., 2009). Due to the current uncertainties regarding the role of sea water constituents in light backscattering processes in the ocean (Stramski et al., 2004), and to the relatively short time series acquired during BOUM (3 days), the present study only represents the first step toward the potential use of $b_{\mathrm{bp}}$ to assess community production loss and gain terms. Second, in contrast to $c_{\mathrm{p}}$ which represents the sum of the particulate absorption and scattering coefficients, $b_{\mathrm{bp}}$ can be assessed from space with a satisfying accuracy (IOCCG, 2006). Recently launched (GOCI, Gestationary Ocean Color Imager, KORDI) and planed (GEOOCAPI, CNES; HR-GEO, ISRO) geostationary spatial ocean color instruments will provide new opportunities to infer biogeochemical processes from space with an increased temporal resolution and provide new insights on biogeochemical fluxes. In that context, a better understanding of $b_{\mathrm{bp}}$ diel cycles is of particular interest. 


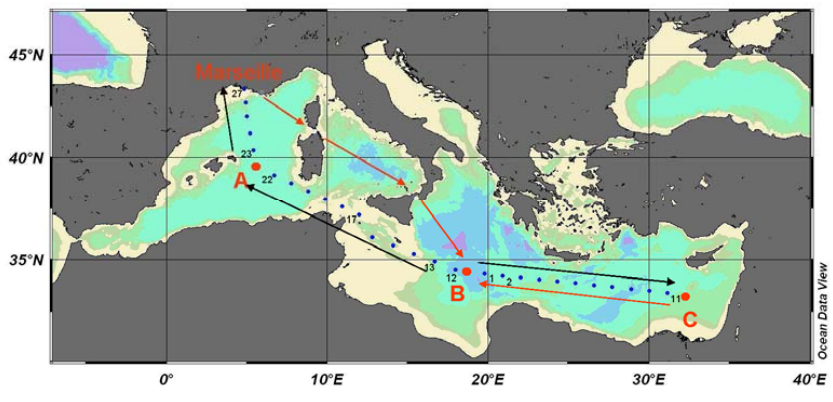

Fig. 1. Transect performed during the BOUM cruise (16 June-20 July 2008). Short duration (SD) stations are reported as blue dots while long duration (LD) stations sampled in the centre of anticyclonic eddies for a time period of 3 days are reported as red dots (namely stations A, B and C).

\section{Materials and methods}

\subsection{Sampling strategy}

The BOUM cruise took place during summer 2008 (from 16 June to 20 July in the Mediterranean Sea and consisted of a $3000 \mathrm{~km}$ transect from the Rhone river mouth (western Mediterranean) to the Eratosthenes sea mount (eastern Mediterranean, Fig. 1). Along this transect, two kinds of stations were sampled: "short duration" (SD) and "long duration" (LD) stations (27 and 3 stations respectively, Fig. 1). Surface to bottom measurements were performed at each SD station distant of around 60 miles of each other. The $3 \mathrm{LD}$ stations (A, B, C) were located in the centre of anticyclonic eddies, approximately determined from satellite imagery and MERCATOR forecast and accurately located on board using hydrologic and hydrodynamic data (i.e. XBT, thermosalinograph and ADCP measurements). The latter fixed stations were sampled at high frequency (every $3 \mathrm{~h}$ ) for 3 days in order to study the diurnal cycle of various biogeochemical and optical parameters. Basic measurements consisted of CTD vertical profiles $(0-500 \mathrm{~m})$. In addition, discrete Niskin bottles samples were taken at different depths of the water column. It is noteworthy that hydrodynamic conditions for the LD fixed stations remained stable all along the sampling time period (Moutin et al., 2011).

\subsubsection{Biogeochemical parameters}

Photosynthetic pigment (including total chlorophyll$a, \quad$ TChl- $a=$ chlorophyll- $a+$ divinyl chlorophyll$a+$ chlorophyllide- $a \mathrm{mg} \mathrm{m}^{-3}$ ) concentrations were measured at discrete depths collected from Niskin bottles (1 to $2.5 \mathrm{~L}$ ) by High Performance Liquid Chromatography (HPLC) following the methodology described in Ras et al. (2008). The relative proportion of pico-, nano- and microphytoplankton was computed using the chemotaxonomic pigment ratios described in Vidussi et al. (2001) recently updated by Uitz et al. (2006). Note that only one vertical profile of HPLC measurements is available at each long duration station.

Particulate organic carbon, POC, (in $\mu g ~^{-1}$ ) was collected on precombusted $(24 \mathrm{~h}, 450 \mathrm{C})$ glass fiber filters (Whatman $\mathrm{GF} / \mathrm{F}, 25 \mathrm{~mm}$ ). Filters were dried in an oven at $50^{\circ} \mathrm{C}$ and stored, in ashed glass vial and in a dessicator until analyses when return from the cruise, on a CHN Perkin Elmer 2400.

For Lithogenic silica, LSi, between 1 and 2.31 of seawater were filtered onto $47 \mathrm{~mm} 0.6 \mu \mathrm{m}$ PC filters. Filters were folded and stored in a plastic Petri dish, oven dried $\left(60^{\circ} \mathrm{C}\right)$ for $24 \mathrm{~h}$ and then stored at room temperature until analyses at the laboratory. Filters were analyzed for LSi following the HF digestion technique described by Nelson et al. (1989).

\subsubsection{Optical measurements}

\section{Remote sensing reflectance}

Hyperspectral radiometric measurements ( $3 \mathrm{~nm}$ resolution) were performed in the $350-750 \mathrm{~nm}$ spectral range with two TriOS radiometers. The first radiometer was fixed on the deck and measured the above-surface downward irradiance, $E_{\mathrm{d}}\left(0^{+}, \lambda\right)$, where $\lambda$ is the wavelength of light in nanometers $(\mathrm{nm})$. The second radiometer recorded the upward radiance profile in the water column, $L_{\mathrm{u}}(\mathrm{z}, \lambda)$. Remotesensing reflectance, $R_{\mathrm{rs}}(\lambda)$, was then calculated from the inwater method, following the protocols prescribed by Mueller (2003):

$R_{\mathrm{rs}}(\lambda)=L_{\mathrm{w}}(\lambda) / E_{\mathrm{d}}\left(0^{+}, \lambda\right)$

where $L_{\mathrm{w}}(\lambda)$ is the water leaving radiance which is calculated from the upwelling radiance just below the sea surface estimated from the $L_{\mathrm{u}}(\mathrm{z}, \lambda)$ vertical profile. A full description of the radiometric data processing is given by Lubac and Loisel (2007).

\section{Chlorophyll fluorescence}

Continuous profiles of chlorophyll fluorescence were measured using a Chelsea Aquatracka III fluorometer and was calibrated to TChl- $a$ concentration using HPLC pigment measurements. In practice, a calibration was made for each LD stations, by linear regression of fluorescence on TChl$a$ from each LD stations profiles and from the nearest transect casts. Calibration relationships slightly differ from one LD station to another due to variation in the phytoplankton community and physiological state (station A: TChl$a=2.5263$ fluo $+0.0038, r^{2}=0.9683, N=89$; station B: TChl- $a=2.3575$ fluo $+0.0059, r^{2}=0.9771, N=30$; station C: TChl- $a=3.0638$ fluo $-0.0097, r^{2}=0.9812, N=30$ ).

\section{Backscattering coefficient}

The particulate backscattering coefficient, $b_{\mathrm{bp}}(\lambda)$, is sensitive to particle load, composition (refractive index), and 
size distribution, and usually dominates the backscattering in coastal waters. However, in open ocean waters the backscattering of pure seawater, $b_{\mathrm{bw}}(\lambda)$, is significant, and uncertainties in this term have a large impact when computing the particulate component (Twardowski et al., 2007). Vertical profiles of the scattering coefficient at $650 \mathrm{~nm}$ and three angles, $100^{\circ}, 125^{\circ}$ and $150^{\circ}$ were performed with a WET Labs ECO-VSF meter during LD stations only. Because of the very oligotrophic conditions encountered during the cruise, which push backscattering measurements near to their limit, dark current measurements were performed in the dark several times during the cruise using a neoprene black cape to cover the instrument window. The obtained values are very similar to those measured before the cruise during the calibration phase at the factory (WET Labs), emphasizing no electronic drift of this parameter. Integration and extrapolation of the measured signal from $90^{\circ}$ to $180^{\circ}$ yield the total backscattering coefficient, $b_{\mathrm{b}}(650)$, after correction for the loss of photons along the path due to absorption by particulate and dissolved material (Loisel et al., 2007). The particulate backscattering coefficient, $b_{\mathrm{bp}}(650)$, is then obtained by correcting the signal for backscattering by pure seawater as described in Loisel et al. (2007). The theoretical model by Zhang et al. (2009) was used to correct for the scattering by pure seawater while absorption correction was performed using in situ discrete measurements.

\section{Beam attenuation coefficient}

Profiles of beam transmission at $650 \mathrm{~nm}$ were measured by a WET Labs Cstar transmissiometer with a $25 \mathrm{~cm}$ pathlength at all stations. Data were processed to give the beam attenuation coefficient, $c(650)$, for sea water, expressed in $\mathrm{m}^{-1}$. In order to get the attenuation coefficient for suspended particles, $c_{\mathrm{p}}(650)$, the contribution from pure seawater has to be subtracted to $c(650)$. Instead of using the factory calibration, the mean $c(650)$ value measured between 350 and $400 \mathrm{~m}$ depth was subtracted from each profile since at these depths, the very low particle concentration induces $c(650)$ values very close to the value for particle-free water. This approach, described by Loisel and Morel (1998), presents the advantage of accounting for the effects of instrumental drift and varying cleanliness of the optical windows. Theoretically, $c_{\mathrm{p}}(650)$ represents the sum of absorption and scattering coefficients, but in practice at $650 \mathrm{~nm}$ it can be assumed that $c_{\mathrm{p}}(650)$ corresponds to the particle scattering coefficient $b_{\mathrm{p}}(650)$ due to very low particulate absorption in the red part of the spectrum, especially for the oligotrophic waters sampled during BOUM (Loisel and Morel, 1998).

\section{Absorption coefficient}

The total particulate absorption coefficient, $a_{\mathrm{p}}(\lambda)$, is the sum of the phytoplankton absorption coefficient, $a_{\mathrm{ph}}(\lambda)$, and the absorption coefficient by non-pigmented particles, $a_{\text {nap }}(\lambda)$. Water samples were taken at $5 \mathrm{~m}$ depth and close to the DCM (Deep Chlorophyll Maximum) during the diel cycle casts. Samples were stored in a cool and dark compartment until filtration, at most $6 \mathrm{~h}$ after collection. Depending on particle content, a volume of 2.8 to 5.61 was filtered onto $25 \mathrm{~mm}$ pre-combusted Whatman GF/F filters, immediately put in liquid nitrogen and stored at $-80{ }^{\circ} \mathrm{C}$ until analysis in the laboratory within two months of sampling. Note that precombustion shrinks the pore size of the GF/F filters for which it is initially assumed that particles with diameter greater than $0.5-0.7 \mathrm{~mm}$ are retained before shrinking. A Cary 100 UV/VIS double-beam spectrophotometer was used for the analysis. The total Optical Density of the particles on the filter, $\mathrm{OD}_{\mathrm{fp}}(\lambda)$, was measured between $300-900 \mathrm{~nm}$. Due to high instrumental noise in the upper and lower ends of the spectrum, only measurements in the range $350-850 \mathrm{~nm}$ were used for further analysis. The absorption coefficient $a_{\mathrm{p}}(\lambda)$ $\left(\mathrm{m}^{-1}\right)$ is computed as

$a_{\mathrm{p}}(\lambda)=2.303 A_{\mathrm{f}} / \beta V_{\mathrm{f}}\left[\mathrm{OD}_{\mathrm{fp}}(l \lambda)-\mathrm{OD}_{\mathrm{bf}}(\lambda)-\mathrm{OD}_{\text {null }}\right]$

where $\operatorname{OD}_{\mathrm{bf}}(\lambda)$ is the optical density of a hydrated blank filter and $\mathrm{OD}_{\text {null }}$ is a residual correction from the infrared spectrum where particle absorption is minimal. When a double-beam spectrometer with automatic baseline correction is used, with a blank filter in one of the filter holders, $\mathrm{OD}_{\mathrm{bf}}$ does not need to be subtracted during the processing. $\mathrm{OD}_{\text {null }}$ is computed as the mean $\mathrm{OD}_{\mathrm{fp}}(\lambda)$ in the interval $790-800 \mathrm{~nm}$. Light scattering within the filter increases the absorption pathlength, and the absorption coefficient must be corrected for this pathlength amplification. The pathlength amplification factor $\beta$ is calculated as

$\beta=\left[C_{1}+C_{2}\left[\mathrm{OD}_{\mathrm{fp}}(\lambda)-\mathrm{OD}_{\mathrm{null}}\right]\right]^{-1}$

The pathlength amplification varies with phytoplankton community and especially cell size. The coefficients $C_{1}$ and $C_{2}$ were set to 0.359 and 0.390 , respectively. These values were obtained from Bricaud et Stramski (1990). Once the $\operatorname{OD}_{\mathrm{fp}}(\lambda)$ has been measured, the pigments are extracted in methanol as described in (Mitchell et al., 2003), and $\mathrm{OD}_{\mathrm{fd}}(\lambda)$ is measured. $a_{\text {nap }}(\lambda)$ is calculated in the same way as $a_{\mathrm{p}}(\lambda)$, replacing $\operatorname{OD}_{\mathrm{fp}}(\lambda)$ with $\mathrm{OD}_{\text {fnap }}(\lambda)$ in Eq. (2). The phytoplankton absorption $a_{\mathrm{ph}}(\lambda)$ is then computed as $a_{\mathrm{p}}(\lambda)-a_{\text {nap }}(\lambda)$.

\subsubsection{Ancillary parameters}

Continuous PAR measurements were recorded on board (1 measure each $30 \mathrm{~s}$ ). In addition, vertical profile of PAR were measured at each station (short and long duration) allowing to compute the euphotic depth (Zeu: depth where the PAR is equal to $1 \%$ of its surface value). The mixed layer depth, MLD, is taken from Moutin et al. (2011) as the MLD 2 days lagged (see their Table 1a). 
Table 1. General bio-optical characteristics of the surface water and at the deep chlorophyll maximum (DCM) at the long duration stations A, $\mathrm{B}$, and $\mathrm{C}$. The values in standard font and bold represent the mean and standard deviation values, respectively. The particulate backscattering $\left(b_{\mathrm{bp}}\right)$ and attenuation $\left(c_{\mathrm{p}}\right)$ coefficients values are given 650 and $660 \mathrm{~nm}$, respectively. The absorption coefficients values are given at $440 \mathrm{~nm}$. The subscripts $\mathrm{p}$, phy, and nap stand for particulate, phytoplankton, and non-algal particles, respectively.

\begin{tabular}{|c|c|c|c|c|c|c|c|}
\hline & St $A_{\text {surf }}$ & StA ${ }_{D C M}$ & $\mathrm{StB}_{\text {surf }}$ & $\mathrm{StB}_{\mathrm{DCM}-1}$ & $\mathrm{StB}_{\mathrm{DCM}-2}$ & $\mathrm{StC}_{\text {surf }}$ & $\mathrm{StC}_{\mathrm{DCM}}$ \\
\hline \multirow[t]{2}{*}{ TChl- $a$} & 0.047 & 0.493 & 0.0423 & 0.126 & 0,199 & 0.033 & 0.462 \\
\hline & $\pm \mathbf{0 . 0 0 7}$ & $\pm \mathbf{0 . 1 3 6}$ & $\pm \mathbf{0 . 0 0 5}$ & $\pm \mathbf{0 . 0 2 4}$ & $\pm \mathbf{0 . 0 2 0}$ & $\pm \mathbf{0 . 0 0 6}$ & $\pm \mathbf{0 . 1 2 7}$ \\
\hline \multirow{2}{*}{$b_{\mathrm{bp}}$} & 0.00081 & 0.00135 & 0.00066 & 0.00077 & 0.00058 & 0.00055 & 0.00089 \\
\hline & $\pm \mathbf{0 . 0 0 0 1}$ & $\pm \mathbf{0 . 0 0 0 3}$ & $\pm \mathbf{0 . 0 0 0 0 8}$ & $\pm \mathbf{0 . 0 0 0 3}$ & $\pm \mathbf{0 . 0 0 0 0 9 1}$ & $\pm \mathbf{0 . 0 0 0 0 6}$ & $\pm \mathbf{0 . 0 0 0 3}$ \\
\hline \multirow[t]{2}{*}{$c_{\mathrm{p}}$} & 0.0541 & 0.0800 & 0.0410 & 0.0551 & 0.0252 & 0.0331 & 0.0565 \\
\hline & $\pm \mathbf{0 . 0 0 3 5}$ & $\pm \mathbf{0 . 0 1 8 2}$ & $\pm \mathbf{0 . 0 0 2 7}$ & $\pm \mathbf{0 . 0 0 8 1}$ & $\pm \mathbf{0 . 0 0 2 0}$ & $\pm \mathbf{0 . 0 0 2 8}$ & $\pm \mathbf{0 . 0 0 9 4}$ \\
\hline \multirow{2}{*}{$b_{\mathrm{bp}} / c_{\mathrm{p}}$} & 0.0150 & 0.0173 & 0.0161 & 0.0141 & 0.0232 & 0.0166 & 0.0158 \\
\hline & $\pm \mathbf{0 . 0 0 1 9}$ & $\pm \mathbf{0 . 0 0 3 8}$ & $\pm \mathbf{0 . 0 0 1 7}$ & $\pm \mathbf{0 . 0 0 5 7}$ & $\pm \mathbf{0 . 0 0 4 0}$ & $\pm \mathbf{0 . 0 0 2 0}$ & $\pm \mathbf{0 . 0 0 4 8}$ \\
\hline \multirow[t]{2}{*}{$b_{\mathrm{bp}} / \mathrm{TChl}-a$} & 0.017 & 0.0028 & 0.0159 & 0.00624 & 0.0029 & 0.017 & 0.002 \\
\hline & $\pm \mathbf{0 . 0 0 3}$ & $\pm \mathbf{0 . 0 0 0 6 7}$ & $\pm \mathbf{0 . 0 0 2 5}$ & $\pm \mathbf{0 . 0 0 2 3}$ & $\pm \mathbf{0 . 0 0 0 6}$ & $\pm \mathbf{0 . 0 0 4}$ & $\pm \mathbf{0 . 0 0 0 7 2}$ \\
\hline \multirow[t]{2}{*}{$c_{\mathrm{p}} /$ TChl- $a$} & 1.1715 & 0.1652 & 0.9824 & 0.4475 & 0.1273 & 1.0397 & 0.1287 \\
\hline & $\pm \mathbf{0 . 1 9 0 9}$ & $\pm \mathbf{0 . 0 2 2 4}$ & $\pm \mathbf{0 . 1 2 7 3}$ & $\pm \mathbf{0 . 0 7 5 3}$ & $\pm \mathbf{0 . 0 1 2 3}$ & $\pm \mathbf{0 . 2 1 7 4}$ & $\pm \mathbf{0 . 0 2 8 7}$ \\
\hline \multirow[t]{2}{*}{$a_{\mathrm{p}}$} & 0.00731 & 0.01808 & 0.00534 & No data & 0.01772 & 0.00464 & 0.02449 \\
\hline & $\pm \mathbf{0 . 0 0 0 1 0}$ & $\pm \mathbf{0 . 0 0 5 4 4}$ & $\pm \mathbf{0 . 0 0 0 4 6}$ & & $\pm \mathbf{0 . 0 0 1 3 0}$ & $\pm \mathbf{0 . 0 0 0 4 2}$ & $\pm \mathbf{0 . 0 0 2 8 3}$ \\
\hline \multirow[t]{2}{*}{$a_{\text {phy }}$} & 0.00461 & 0.01319 & 0.00359 & No data & 0.01411 & 0.00274 & 0.01864 \\
\hline & $\pm \mathbf{0 . 0 0 1 0}$ & $\pm \mathbf{0 . 0 0 4 4 3}$ & $\pm \mathbf{0 . 0 0 0 3 0}$ & & $\pm \mathbf{0 . 0 0 1 3 9}$ & $\pm \mathbf{0 . 0 0 0 2 7}$ & $\pm \mathbf{0 . 0 0 2 0 0}$ \\
\hline \multirow{2}{*}{$a_{\text {nap }}$} & 0.00270 & 0.00489 & 0.00176 & No data & 0.00361 & 0.00189 & 0.00584 \\
\hline & $\pm \mathbf{0 . 0 0 0 3 2}$ & $\pm \mathbf{0 . 0 0 1 2 4}$ & $\pm \mathbf{0 . 0 0 0 3 4}$ & & \pm 0.00056 & \pm 0.00040 & $\pm \mathbf{0 . 0 0 1 0 3}$ \\
\hline \multirow[t]{2}{*}{$a_{\text {phy }} / a_{\mathrm{p}}$} & 0.625 & 0.725 & 0.673 & No data & 0.796 & 0.594 & 0.761 \\
\hline & $\pm \mathbf{0 . 0 5 1 3}$ & $\pm \mathbf{0 . 0 5 0 8}$ & $\pm \mathbf{0 . 0 4 8 1}$ & & $\pm \mathbf{0 . 0 3 3 6}$ & $\pm \mathbf{0 . 0 6 1 2}$ & $\pm \mathbf{0 . 0 2 2 1}$ \\
\hline \multirow[t]{2}{*}{$a_{\mathrm{p}} / \mathrm{TChl}-a$} & 0.157 & 0.06226 & 0.128 & No data & 0.10872 & 0.145 & 0.06235 \\
\hline & $\pm \mathbf{0 . 0 3 6}$ & $\pm \mathbf{0 . 0 1 3 1 5}$ & $\pm \mathbf{0 . 0 1 6}$ & & \pm 0.00804 & $\pm \mathbf{0 . 0 2 8}$ & $\pm \mathbf{0 . 0 1 8 7 7}$ \\
\hline \multirow[t]{2}{*}{$a_{\text {phy }} /$ TChl- $a$} & 0.099 & 0.04490 & 0.086 & No data & 0.08642 & 0.086 & 0.04765 \\
\hline & $\pm \mathbf{0 . 0 3 1}$ & $\pm \mathbf{0 . 0 0 9 3 8}$ & $\pm \mathbf{0 . 0 1 0}$ & & \pm 0.00669 & $\pm \mathbf{0 . 0 1 9}$ & \pm 0.01484 \\
\hline
\end{tabular}

\subsection{Production model}

Diel variation in the POC estimates obtained from $c_{\mathrm{p}}$ can be used to assess various terms of a production budget including gross community production, community losses or net community production rates following the method documented by Claustre et al. (2008). This method is also applied here for $b_{\mathrm{bp}}$.

For a given ocean layer, the gross community production derived from optical measurements $\left({ }^{\mathrm{Opt}} \mathrm{GCP}\right.$ in $\mathrm{mgC} \mathrm{m}^{-2} \mathrm{~d}^{-1}$ ) is the sum of the gross primary and microbial productions. It can be assessed by estimation of the increase in POC content during daytime (D $\triangle \mathrm{POC}$ ). In practice:

${ }^{\mathrm{Opt}} \mathrm{GCP}=D \Delta \mathrm{POC} / D t$

where $D t$ is equal to the day time duration corresponding to each day sampled. In practice we considered the difference between minimum and maximum POC values for the calculation of the later biogeochemical rates rather than the actual POC values corresponding to the sunlight diel evolution (see in Sect. 3.4). Similar estimation of the Net Community Production ( ${ }^{\mathrm{Opt}} \mathrm{NCP}$ in $\mathrm{mg} \mathrm{Cm}^{-2} \mathrm{~d}^{-1}$ ) and of the community losses ( ${ }^{\mathrm{Opt}} \mathrm{CL}$ i.e. respiration and other processes such as grazing and sinking) can be performed following the POC evolution during nighttime, however the latter are not considered for this study due to the absence of concurrent estimation of these biogeochemical rates from classical methods prevailing any validation of the derived estimates.

\section{Results and discussion}

\subsection{Vertical distribution of the particulate matter}

\subsubsection{Vertical profile of fluorescence and pigment-derived phytoplankton size classes}

Vertical profiles of the total chlorophyll- $a$ concentration, TChl- $a$, estimated from in situ fluorescence calibrated using discrete HPLC measurements (see material and method), present a general feature typical of oligotrophic conditions. A deep chlorophyll maximum is found within the stratified part of the water column (Fig. 2a, c, e). This maximum is observed at 85 and $110 \mathrm{~m}$ for the $\mathrm{A}$ and $\mathrm{C}$ long duration stations, respectively. These water depths roughly correspond to the depths of the euphotic zone ( $83 \mathrm{~m}$ for A, and $102 \mathrm{~m}$ for C) and are slightly deeper than the top of the nitricline which were observed at 72, and $93 \mathrm{~m}$, respectively (Moutin et al., 2011). These results are in good agreement with previous 
studies performed in oligotrophic areas (Moutin and Raimbault, 2002; Marty et al., 2002; Letelier et al., 2004; Uitz et al., 2006). The TChl- $a$ values at the DCM are 0.49 and $0.46 \mathrm{mg} \mathrm{m}^{-3}$ which, compared to their surface values, correspond to an increase in TChl- $a$ with depth by a factor of 10.5 and 14 , respectively. In contrast to these two stations, the TChl- $a$ profile at station B is characterized by two unusual maxima (75 and $140 \mathrm{~m}$ ) which are located above the euphotic depth $(104 \mathrm{~m})$ and below the top of the nitricline $(114 \mathrm{~m})$. Note that these TChl- $a$ values slightly differ from the one reported in Moutin et al. (2011) who used a single parameterization to convert the in situ fluorescence signal in terms of TChl $-a$ for the three profiles measured at the LD stations $\mathrm{A}, \mathrm{B}$ and $\mathrm{C}$, while different parameterizations were used for each LD station in the present manuscript. The surface TChl$a$ concentration at station $\mathrm{B}$ is equivalent to those of stations A and C, but increases only by a factor of 3 and 4.7 from the surface to the first and second maximum, respectively. Chl- $a$ concentration as measured from HPLC does not change between 75 and $150 \mathrm{~m}\left(=0.0845 \pm 0.0062 \mathrm{mg} \mathrm{m}^{-3}\right)$, whereas Divinyl-chlorophyll- $a$ presents a peak at $124 \mathrm{~m}$ (Fig. 2c). As already discussed in several papers, the DCM is partly explained by an intracellular increase in Chl- $a$ (Kiefer et al., 1976; Cullen, 1982). Indeed, the phytoplankton community physiologically adapts to the low irradiance level (the so called photoacclimation process), and to the vicinity of the top of the nitricline. The recent development of appropriate in situ instrumentation to characterize the vertical profile of marine particles also highlights that phytoplankton cells can play, through photoadaptation process, an important role in this vertical feature (Oubelkier and Sciandra, 2008; Grob et al., 2007). For instance, cytometry measurements performed in the Ionian Sea show a maximum of picophytoeukaryotes in the 50-90 m layer, with a deep chlorophyll maximum located at $90 \mathrm{~m}$ (Oubelkier and Sciandra, 2008). In the same way, a deep picophytoeukaryotes maximum was recorded in the deep chlorophyll maximum at the center of the South Pacific gyre (Grob et al., 2007).

Vertical profiles of pigment-derived phytoplankton size classes as proposed by Claustre (1994) and Vidussi et al. (2001) and recently improved by Uitz et al. (2006) reveal a change in the phytoplankton community structure over the water column (Fig. 2b, d, f). Within the surface layer, the biomass in terms of TChl- $a$, is dominated by nanophytoplankton, with a proportion of $68 \%, 55 \%$, and $60 \%$ at stations A, B, and C, respectively. The proportion of nanophytoplankton then decreases from the surface to the deep chlorophyll maximum, from where it starts increasing. The phytoplankton community structure is equally dominated by pico and nano -phytoplankton at the DCM for stations A and C. This is in agreement with cytometry counting and microscopic identification (Mauriac et al., 2011). At station B, while the first DCM shows more nano-phytoplankton (52\%) than pico-phytoplankton (35\%), the second DCM is mainly dominated by pico-phytoplankton $(65 \%)$. This diversity in
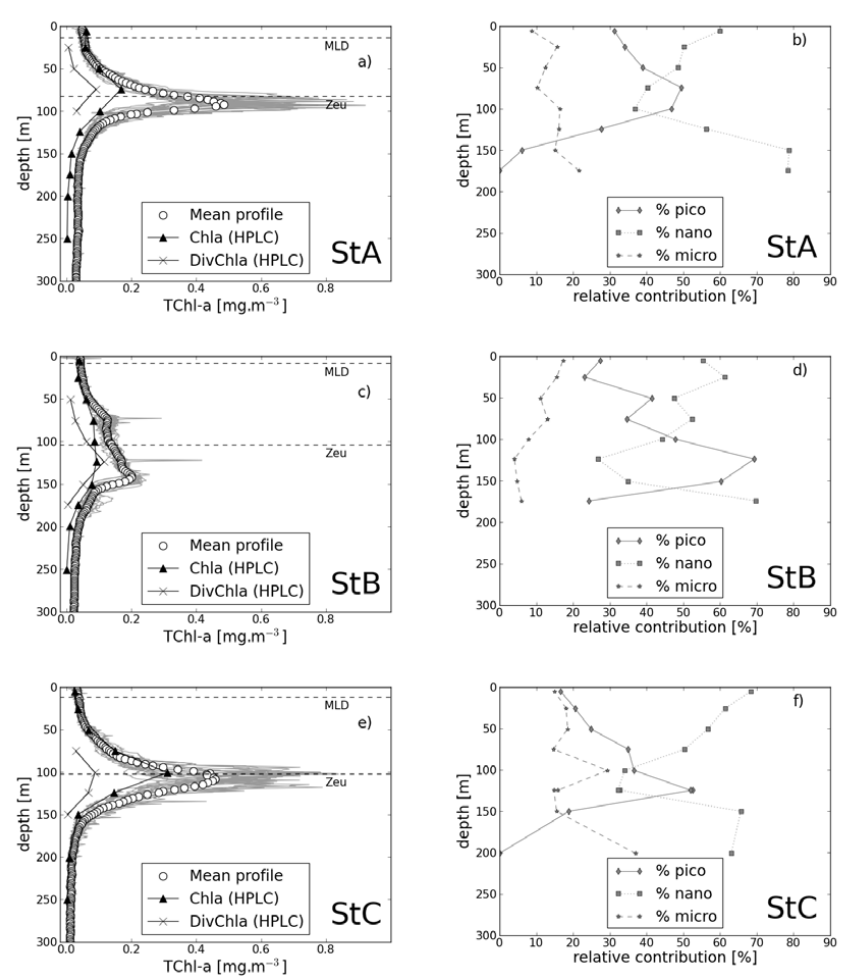

Fig. 2. Vertical profiles of calibrated fluorescence performed during the whole time period of sampling at the long duration stations A (a), B (c), and C (e), together with the discrete measurements of chlorophyll- $a$ and divinyl chlorophyll- $a$ performed by HPLC (see text). Vertical profiles of the relative proportion of pico-, nano- and microphytoplankton at the long duration stations A (b), B (d), and C (f). The depth of the euphotic zone, Zeu, and the lower limit of the mixed layer, MLD, are indicated.

the phytoplankton assemblages at the two DCM of station B which are characterized by the same Chl- $a$ (as measured by HPLC) could explain the difference observed in the fluorescence peak intensity.

\subsubsection{Vertical profiles of particulate attenuation and backscattering coefficients}

Particulate attenuation (Fig. 3a, c, e) and backscattering (Fig. 3b, d, f) coefficients were also acquired simultaneously to fluorescence profiles. The main vertical patterns observed in the fluorescence profiles are also identified for the $c_{\mathrm{p}}$ and $b_{\mathrm{bp}}$ ones. In particular, both $c_{\mathrm{p}}$ and $b_{\mathrm{bp}}$ present a maximum located at the DCM, and their value greatly decreases below. However, some differences are noticeable. Firstly, while TChl- $a$ sharply increases from the surface to the DCM, this increase is much less pronounced for both $c_{\mathrm{p}}$ and $b_{\mathrm{bp}}$ at each long duration stations. For instance, while TChl- $a$ increases by a factor of about $20, c_{\mathrm{p}}$ and $b_{\mathrm{bp}}$ only increase by a factor of 1.9 and 1.6, respectively at station $\mathrm{C}$ (Table 1 ). Secondly, the two TChl- $a$ maxima measured at station B are 

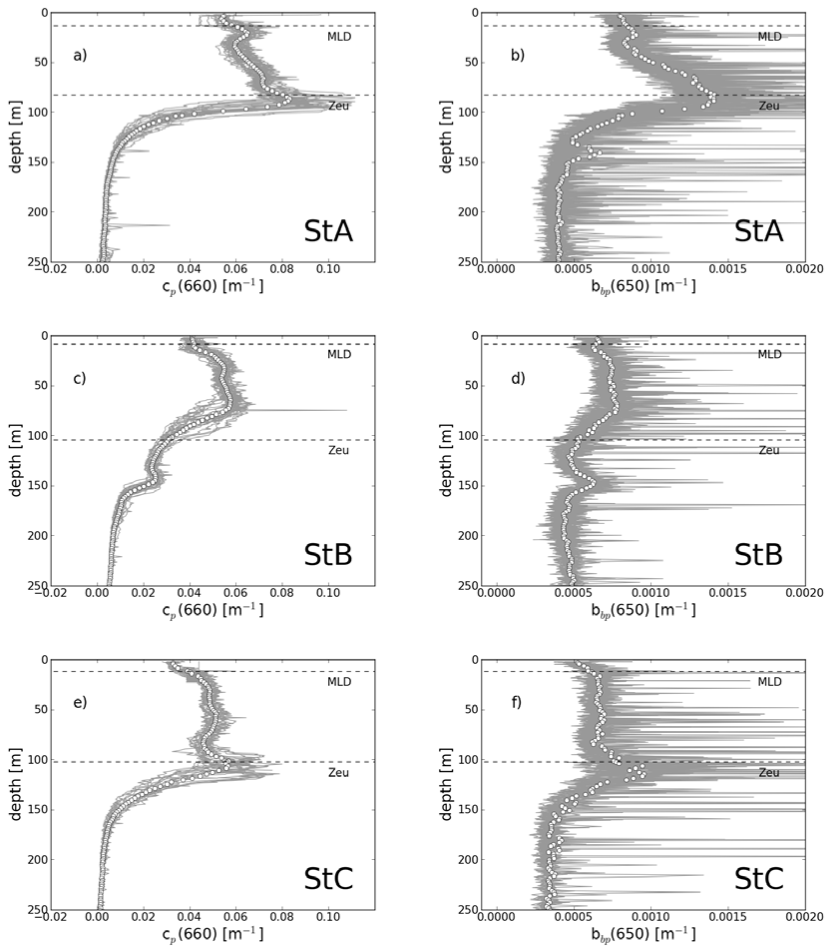

Fig. 3. Vertical profiles of the particulate attenuation coefficient at $660 \mathrm{~nm}, c_{\mathrm{p}}(660)$, for the LD stations A (a), B (c), and C (e). Vertical profiles of the particulate backscattering coefficient at $650 \mathrm{~nm}$, $b_{\mathrm{bp}}(650)$, for the LD stations A (b), B (d), and C (f). The depth of the euphotic zone, Zeu, and the lower limit of the mixed layer, MLD, are indicated.

also observable on the $c_{\mathrm{p}}$ profiles but their intensity is reversed. From the first $(z=75 \mathrm{~m})$ to the second $(z=140 \mathrm{~m})$ peak the $c_{\mathrm{p}}$ value decreases by a factor of 2.2, whereas TChl$a$ increases by a factor of 1.6. Thirdly, two $c_{\mathrm{p}}$ maxima (at 22 and $85 \mathrm{~m}$ ) are also observable at station A, where only one TChl- $a$ maximum is measured. Finally, compared with the fluorescence and particulate attenuation profiles, particulate backscattering profiles exhibit numerous brief and large spikes, which may be related to the presence of either aggregates or zooplankton (Bishop et al., 1999; Gardner et al. 2000).

A combination of vertical profiles of particulate scattering coefficients and fluorescence profiles have previously been used to explain the origin of variability of TChl- $a$ within the whole water column (Kitchen and Zaneveld, 1990; Loisel and Morel, 1998). The $c_{\mathrm{p}}$ vs. TChl- $a$ diagrams, characterized by a 7-shape, are typical of oligotrophic environments (Fig. 4). Between the surface and the DCM, $c_{\mathrm{p}}$ is more or less constant, and then linearly decreases with TChl- $a$ toward the deeper aphotic level. The horizontal segment observed from surface waters to the DCM illustrates the photoacclimation process responsible for the intraspecific variation in the cellular chlorophyll concentration. The $c_{\mathrm{p}}$
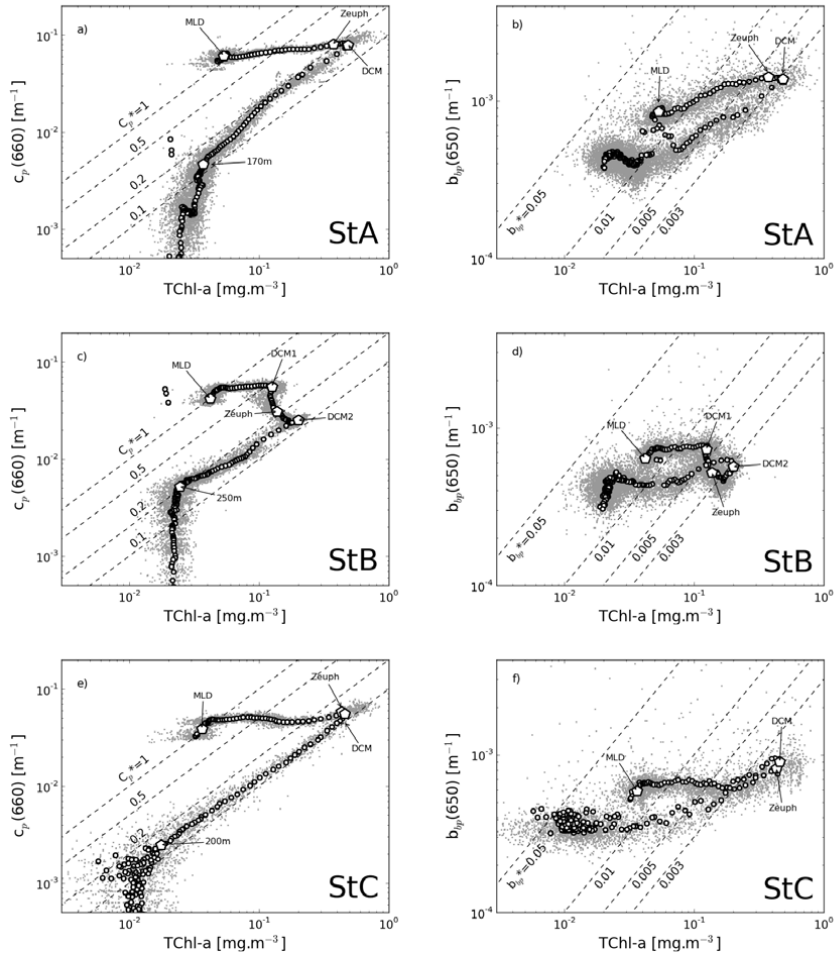

Fig. 4. $c_{\mathrm{p}}(660)$ (left panels) and $b_{\mathrm{bp}}(650)$ (right panels) as a function of TChl- $a$ through the whole water column at stations A, B, and $\mathrm{C}$ as indicated. The lines drawn with a 1:1 slope correspond to values of the specific particulate attenuation, $c_{\mathrm{p}} *\left(=c_{\mathrm{p}} / \mathrm{TChl}-a\right)$, and backscattering, $b_{\mathrm{bp}} *\left(=b_{\mathrm{bp}} / \mathrm{TChl}-a\right)$, coefficients in $\mathrm{m}^{2}$ (mg TChl$a)^{-1}$. The depths of the euphotic zone, Zeu, of the lower limit of the mixed layer, MLD, and of the deep chlorophyll maximum, DCM, are indicated. The numerical depth values (e.g. 170, 250, and $200 \mathrm{~m}$ ) indicate the depth, deeper than the DCM, from which the $\log \left(c_{\mathrm{p}}(660)\right)$ vs. $\log (\mathrm{TChl}-a)$ relationship departs from linearity.

vs. TChl- $a$ linear behavior observed below the DCM can be interpreted as a progressive dilution of the entire particulate matter assemblage seen by the transmissometer (Loisel and Morel, 1998). Values of the specific particulate coefficient, $c_{\mathrm{p}} *\left(=c_{\mathrm{p}} / \mathrm{TChl}-a\right)$, vary between about 1 and $0.1 \mathrm{~m}^{2}$ (mg TChl- $a)^{-1}$ from the surface layer to the DCM for the three long duration stations. The linear trend observed below the DCM is characterized by $c_{\mathrm{p}} *$ values of $0.1-0.2 \mathrm{~m}^{2}$ $(\mathrm{mg} \mathrm{TChl}-a)^{-1}$. These different $c_{\mathrm{p}}{ }^{*}$ values are typical of those found in other oligotrophic environments (Loisel and Morel, 1998; Gardner et al., 2006; Morel et al., 2007).

The two DCMs at station B are also clearly visible on the $c_{\mathrm{p}}$ vs. TChl- $a$ diagram. The photoacclimation of phytoplankton cells is evidenced by the horizontal segment from the surface layer to the first DCM, with $c_{\mathrm{p}} *$ value decreasing by a factor of 2 (from 1 to $0.5 \mathrm{~m}^{2}(\mathrm{mg} \mathrm{TChl}-a)^{-1}$ ). Then, while TChl- $a$ increases by a factor of 1.58 between the first and the second DCM, $c_{\mathrm{p}}$ decreases by a factor of 2.2 , inducing 
$c_{\mathrm{p}} *$ to decrease by a factor of about 5 . Such high $c_{\mathrm{p}}{ }^{*}$ variability observed over a relatively thin water layer $(65 \mathrm{~m})$ may be caused by different factors. The value of $c_{\mathrm{p}} *$ at $660 \mathrm{~nm}$, which is equivalent to $b_{\mathrm{p}}{ }^{*}$ (see material and method), is driven by the scattering cross section of the microbial organisms (function of their refractive index and size distribution), as well as by the relative proportion between detritus and living material. Similarly to stations A and C, this ratio decreases from the surface layer to the first and second DCM in station $B$, in agreement with the evolution of the carbon-to-chlorophyll ratio of phytoplankton cells (Stramski and Reynolds, 1993). Note however that $c_{\mathrm{p}}$ increases by a factor of 1.34 from the surface to the first DCM, probably due to the presence of detritus or other non-pigmented particles, and decreases by a factor of 2.2 between the two DCM due to the adaptation of phytoplankton carbon content to the irradiance level (Table 1).

The two distinct vertical patterns observed for the $c_{\mathrm{p}}$ vs. TChl- $a$ relationship (i.e. the 7-shape) are much less noticeable for the particulate backscattering coefficient. The evolution of $b_{\mathrm{bp}}$ as a function of TChl- $a$ from the surface layer to the DCM is nearly similar to that observed below the DCM. In contrast to $c_{\mathrm{p}}, b_{\mathrm{bp}}$ tends to increase with TChl- $a$ from the surface to the DCM, especially for stations A and C. While $c_{\mathrm{p}} *$ is roughly constant from the DCM to deep waters, $b_{\mathrm{bp}} *$ exhibits large variations of similar amplitude for the two oceanic layers located above or below the DCM. Variation of $b_{\mathrm{bp}} *$ from 0.003 to $0.01 \mathrm{~m}^{2}$ (mg TChl- $\left.a\right)^{-1}$ is found within these two oceanic layers, for instance at station A. For the same range of TChl- $a$, variations in $b_{\mathrm{bp}} *$ computed from Huot et al. (2008)'s formulation gives 0.002 and $0.005 \mathrm{~m}^{2}$ $(\mathrm{mg} \mathrm{TChl}-a)^{-1}$. These values are consistent with the $b_{\mathrm{bp}}$ * measurements performed around the DCM, but are significantly lower than those measured within the surface waters (by a factor of 2). The differences observed between the $c_{\mathrm{p}}$ vs. TChl- $a$ and $b_{\text {bp }}$ vs. TChl- $a$ vertical patterns certainly reflect variation in the sensitivity of $b_{\mathrm{bp}}$ and $c_{\mathrm{p}}$ regarding the nature of the whole particulate matter. The origins of these differences are discussed in the following section.

\subsection{The bio-optical environment of the particulate matter at the three long duration stations}

Relationships between inherent optical properties (IOPs) and biogeochemical parameters are analyzed for the three long duration stations to establish their bio-optical environment, which in turn is compared with standard relationships previously developed for open ocean waters.

The behavior of the particulate, $a_{\mathrm{p}}(440)$, and phytoplankton, $a_{\text {phy }}(440)$, absorption coefficients are analyzed as a function of the total chlorophyll- $a$ concentration, TChl- $a$ (Fig. 5). The variation of $a_{\text {phy }}(440)$ and $a_{\mathrm{p}}(440)$ versus TChl- $a$ from the surface water to the DCM can be described by the following relationships:

$a_{\text {phy }}(440)=0.0364$ TChl- $a^{0.708}\left(N=125, r^{2}=0.89\right)$ $a_{\mathrm{p}}(440)=0.0432 \mathrm{TChl}-a^{0.622}\left(N=125, r^{2}=0.91\right)$

where $\mathrm{N}$ is the number of samples, and $r^{2}$ is the determination coefficient. The non-linear character of these two relationships is particularly consistent with previous studies (Yentsch and Phinney, 1989; Bricaud et al., 1995, 1998). Exponents in Eqs. (5) and (6) are relatively close to each other, emphasizing that absorption by non-algal particles is proportional to phytoplankton absorption at $440 \mathrm{~nm}$. On average, phytoplankton absorption contributes to $62 \pm 5,67 \pm 5$, and $59 \pm 6 \%$ of the particulate absorption measured at $440 \mathrm{~nm}$ in surface waters of LD stations A, B, and C, respectively. These proportions are consistent with previous studies performed in the Mediterranean Sea (Bricaud et al., 1998; Oubelkheir et al., 2007). These proportions significantly increase around the DCM to reach about $70 \%$ (Table 1). The exponents in equations 5 and 6 are similar to previous findings established from large data sets made of in situ measurements collected in various oceanic regions (Bricaud et al., 1995, 1998, 2004; Dupouy et al., 2003). For a given chlorophyll concentration, the values of $a_{\mathrm{p}}(440)$ and especially of $a_{\text {phy }}(440)$ measured in the surface layer during the BOUM cruise are however lower than the mean values previously published. For instance, the mean specific phytoplankton absorption coefficients, $a_{\mathrm{phy}} *\left(=a_{\text {phy }} / \mathrm{TChl}-a\right)$, measured in the surface layer of station $\mathrm{A}$, is lower by a factor of 1.5 and 1.1 compared to the mean values given in Bricaud et al. (2004) and Bricaud et al. (1995), respectively (see Table 1). However, the $a_{\text {phy }}{ }^{*}$ values measured at the three long duration stations are in the range of the natural variability of $a_{\mathrm{phy}} *$ reported by Bricaud et al. (2004), and very close to the ones measured during the MINOS cruise in the Mediterranean Sea (see their Fig. 2a). For the same TChl- $a$ range (about 0.02$0.05 \mathrm{mg} \mathrm{m}^{-3}$ ), the BOUM $a_{\text {phy }}$ * values are also in agreement with those obtained in ultra-oligotrophic waters sampled in the South Pacific Gyre during the BIOSOPE cruise (Bricaud et al., 2010).

The relative low $a_{\text {phy }}$ values reported in the present study compared to the values generally adopted in open ocean waters can be explained by a difference in the size structure and accessory pigments of the phytoplankton assemblage. The phytoplankton size index (SI) values, calculated as in Bricaud et al. (2004), are in the upper limit of the reported values by Bricaud et al. (2010) measured in ultraoligotrophic waters sampled during BIOSOPE. Based on HPLC measurements, the SI (and TChl- $a$ ) values at stations A, B, and C are $11.1\left(0.06 \mathrm{mg} \mathrm{m}^{-3}\right), 11.7\left(0.04 \mathrm{mg} \mathrm{m}^{-3}\right)$, and $7.7\left(0.026 \mathrm{mg} \mathrm{m}^{-3}\right)$, respectively. These relatively high SI values explain the low $a_{\text {phy }}$ coefficient through the packaging effect (Morel and Bricaud, 1981). Concerning accessory pigments, while the ratio values of photosynthetic carotenoids, i.e., fucoxanthin, peridinin, 19'-HF and 19'-BF; to TChl- $a$ are in the range of expected values, the non photosynthetic pigments (zeaxanthin, diadinoxanthin, alloxanthin, and $\beta$-carotene) to TChl- $a$ ratio values are very low (about 

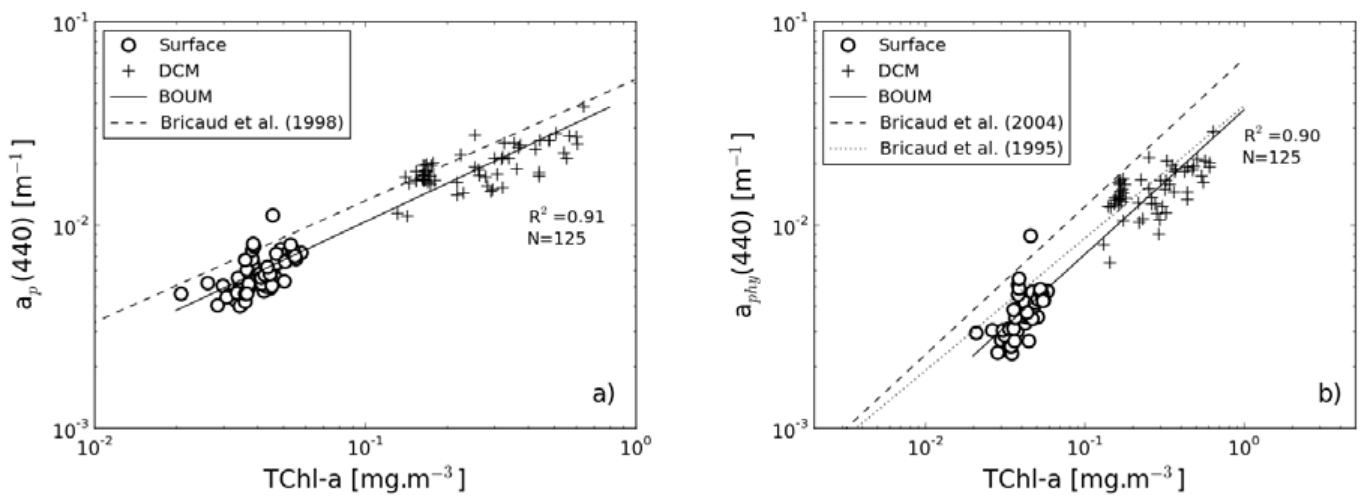

Fig. 5. Variations of the absorption coefficient of (a) particles, $a_{\mathrm{p}}(440)$, and (b) phytoplankton, $a_{\text {phy }}(440)$, at $440 \mathrm{~nm}$ as a function of the TChl- $a$ concentration for the surface layer (open circles), and at the DCM (crosses). The solid curves stand for the regression fits corresponding to Eqs. (6) and (5) from measurements performed at the surface and DCM. Previous relationships are also represented as indicated.

0.15-0.33). These two factors (i.e. relatively high SI and low non photosynthetic pigments to TChl- $a$ ratio), which both explain the relatively low $a_{\text {phy }}$ values, are consistent with a significant contribution of nanophytoplankton to the total phytoplankton biomass. The same conclusion was reached by Bricaud et al. (2010) for the phytoplankton absorption measurements performed in the very clear water of the South Pacific Gyre.

The behavior of $c_{\mathrm{p}}(66 \mathrm{w})$ with Chl- $a$, and POC has been studied in various parts of the global ocean for about 3 decades (Gordon and Morel, 1983; Loisel and Morel, 1998; Gardner et al., 1999; Stramska et al., 2005). In contrast, open ocean water field measurements of the particulate backscattering coefficient, $b_{\mathrm{bp}}(66 \mathrm{w})$, are relatively scarce and restricted to few oceanic areas given that the proper in situ commercial instrumentation has been made available only for about a decade (Stramski et al., 1999; Reynolds et al., 2001; Boss et al., 2004; Huot et al, 2008). The first order variability of both $c_{\mathrm{p}}(66 \mathrm{w})$ and $b_{\mathrm{bp}}(66 \mathrm{w})$ can be used to assess the concentration of the particulate assemblage. Based on Mie scattering theory, which assumes that suspended particles are homogeneous spheres, more than $80 \%$ of the scattering signal is due to particles less than $8 \mu \mathrm{m}$ in diameter. In contrast, for the same particle size distribution (a Junge type with an exponent of -4 ), and a mean refractive index relative to water of 1.05 (typical of phytoplankton cells), most of the backscattering signal is caused by particles smaller than about $1 \mu \mathrm{m}$ (Stramski and Kieffer, 1991; Morel and Ahn, 1991). However, recent fractionation experiments performed in the open ocean (Dall'Olmo et al., 2009) and in coastal waters (Roesler and Boss, 2008) indicate contributions to $b_{\mathrm{bp}}$ from particles larger than $3 \mu \mathrm{m}$ of $53 \pm 7 \%$ (at $470 \mathrm{~nm}$ ) and about $70 \%$ (at $440 \mathrm{~nm}$ ), respectively, and much lower contributions (10-30\%) from submicron particles. The origin of the $b_{\mathrm{bp}}$ signal is then still controversial and more laboratory experiments and in situ measurements are needed to explain the variability observed in the particulate backscattering signal (Stramski et al., 2004).

The (TChl- $a, c_{\mathrm{p}}$ ) data points obtained at the surface for the long $(N=69)$ and short $(N=106)$ duration stations fall within the range of variability obtained over a larger data set (Loisel and Morel, 1998), which covers different oceanic regions, and are in agreement with previous measurements performed in the Mediterranean Sea during the PROSOPE (French acronym for "Productivité des Systèmes Océaniques PElagiques" or "productivity of oceanic pelagic systems") cruise in September 1999 (Oubelkheir et al., 2005) (Fig. 6). The standard non-linear behavior of $c_{\mathrm{p}}(660)$ with TChl- $a$ is well characterized from the surface water measurements performed at the three LD stations (Fig. 6a):

$c_{\mathrm{p}}(660)=0.499 \mathrm{TChl}-a^{0.77}\left(N=69, r^{2}=0.56\right)$

While the exponent 0.77 is remarkably close to the one found in Loisel and Morel (1998) for the upper homogeneous layer of the ocean, the coefficient $(0.499)$ falls above the previously published values. For instance, this coefficient has been fixed at 0.26 from measurements performed within the upper layer of the eastern South Pacific Ocean (Huot et al., 2008), and varies between 0.103 and 0.383 depending on the data set used over different regions of the global ocean (Loisel and Morel, 1998). The relationship described in Eq. (7) is similar to the one established using all the surface measurements performed at short duration stations:

$c_{\mathrm{p}}(660)=0.574 \mathrm{TChl}-a^{0.81}\left(N=106, r^{2}=0.64\right)$

The exponent in Eq. (7) is closer to those obtained in Loisel and Morel (1998) when all pairs of available data are considered (their subset $1+2+3$ in Table 2 ), and larger to the one obtained when data measured in the north Atlantic ocean are excluded (their Subset. 1). The mean surface specific particulate attenuation coefficients, $c_{\mathrm{p}} *\left(=c_{\mathrm{p}} / \mathrm{TChl}-a\right)$, at stations A, $\mathrm{B}$, and $\mathrm{C}$, are $1.17 \pm 0.19,0.98 \pm 0.13$, and $1.04 \pm 0.21 \mathrm{~m}^{2}$ 
$(\operatorname{mg~TChl}-a)^{-1}$ (Table 1). These values are significantly higher than those calculated using the mean global relationships (Subset. $1+2+3$ ) of Loisel and Morel (1998) which are $0.71,0.73$, and $0.77 \mathrm{~m}^{2}(\mathrm{mg} \mathrm{TChl}-a)^{-1}$ at stations A, B, and $\mathrm{C}$, respectively. Note that the BOUM surface $c_{\mathrm{p}}{ }^{*}$ values are consistent with those measured in oligotrophic waters sampled during the PROSOPE cruise (Fig. 6a).

A tight relationship is also observed between $c_{\mathrm{p}}$ and TChl$a$ at the DCM (Fig. 6b):

$c_{\mathrm{p}}(660)=0.152 \mathrm{TChl}-a^{1.08}\left(N=67, r^{2}=0.9\right)$

Note that $c_{\mathrm{p}}$ vs. TChl- $a$ relationship is closer to linearity in the DCM (Eq. 9) than in surface waters (Eq. 7). This relationship is equivalent to the one established for the short duration stations (not shown). Compared with surface waters, the variability in $c_{\mathrm{p}}$ is more tightly related to that of TChl- $a$ at the DCM, as stressed by the relatively high determination coefficient found for the latter relationship. The mean specific attenuation coefficient decreases from the surface water to the DCM by a factor of $6.4,7.7$, and 5.2 at stations A, B (second maximum), and $\mathrm{C}$ (Table 1).

In situ $c_{\mathrm{p}}$ measurements have been extensively used to assess the spatio-temporal variability of POC in open ocean waters (Marra et al., 1995; Loisel and Morel, 1998; Claustre et al., 1999; Karageorgis et al., 2008). The conversion factor between $c_{\mathrm{p}}$ and POC, namely the attenuation cross section, depends on the refractive index, particle size distribution, shape and internal structure of the particles in suspension. Despite the large natural variability of these different parameters, relatively similar relationships have been established between $c_{\mathrm{p}}$ and POC in different oceanic regions (Fig. $3 \mathrm{c}$ in Stramska et al., 2005). For the surface waters (Eq. 10) of the BOUM stations, POC is related to $c_{\mathrm{p}}$ as follows:

$$
P O C=404 . c_{\mathrm{p}}(660)+29.25\left(N=31, r^{2}=0.6\right)
$$

This equation was developed using mainly the short stations, since only two POC profiles were measured during each long duration stations. The coefficient 404 is in the range of previously published values used to convert $c_{\mathrm{p}}$ into POC (see references in Stramska et al., 2005). The relationship between POC and $c_{\mathrm{p}}$ presents much less variability from the surface layer to the DCM (not shown) than the $c_{\mathrm{p}}$ vs. TChl- $a$ relationship which greatly changes along the water column. This is explained by the fact that the vertical profiles of POC are much more constant than those of TChl- $a$, as already shown previously (Duforêt-Gaurier et al., 2010).

The evolution of $b_{\mathrm{bp}}$ as a function of TChl- $a$ (Fig. 7) significantly differs between surface waters (Eq. 11) and the DCM (Eq. 12):

$b_{\text {bp }}(650)=0.00573 \mathrm{TChl}-a^{0.67}\left(N=68, r^{2}=0.59\right)$

$b_{\mathrm{bp}}(650)=0.00197 \mathrm{TChl}-a^{0.75}\left(N=66, r^{2}=0.75\right)$

Similarly to the $c_{\mathrm{p}}$ vs. TChl- $a$ relationships established at the surface and DCM, the exponents in Eqs. (11) and (12) are relatively similar, but the coefficients sharply decrease from the surface to the DCM. Between these two layers, the specific backscattering coefficients, $b_{\mathrm{bp}} / \mathrm{TChl}-a$, decrease by a factor 3 to 5, depending on the station (Table 1). This vertical pattern stresses that the bulk particulate matter is a much more efficient backscatter at the surface than at the DCM for the same TChl- $a$. Note that the $b_{\mathrm{bp}} / \mathrm{TChl}-a$ mean values are remarkably similar between the three long duration stations (Table 1).

The evolution of $b_{\mathrm{bp}}$ as a function of TChl- $a$ established during the BOUM cruise is compared with the empirical formulation documented by Huot et al. (2008), and with the semi-analytical model of Morel and Maritorena (2001). In the latter, the mean formulation used between $b_{\mathrm{p}}$ and TChl- $a$ (Loisel and Morel, 1998) is replaced by the empirical formulation developed over the BOUM data set (Eq. 7), and two different values of the backscattering ratio, $b_{\mathrm{bp}} / b_{\mathrm{p}}$, are successively used: $2 \%$ as in Morel (1988), and $1 \%$ as in Morel and Maritorena (2001) who decreases the Morel (1988)'s value on the basis of theoretical considerations. The $b_{\mathrm{bp}}$ BOUM parameterization (Eq. 11) follows the same trend with TChl- $a$ compared to the three other models, especially the one developed by Huot et al. (2008) which presents exactly the same exponent than in Eq. (11) (Fig. 7a). However, for a given chlorophyll concentration, the bulk particulate matter suspended in the surface water of the long duration stations backscatters light much more efficiently than what is expected for oligotrophic waters. Considering for instance a TChl- $a$ of $0.05 \mathrm{mg} \mathrm{m}^{-3}, b_{\mathrm{bp}}$ calculated using Eq. (11) is greater by a factor of 3.3 compared to the value computed using the Huot et al. (2008)'s model. The dispersion of the Huot et al. (2008) data points, as represented by their $95 \%$ confidence interval, does even not overlap part of the BOUM data set (Fig. 7a). A relatively good agreement can be observed between the BOUM data set and the Morel and Maritorena (2001)'s model when the greatest particulate backscattering ratio value (2\%) is used and when $b_{\mathrm{p}}$ vs. TChl- $a$ is modeled using Eq. (7) instead of the Loisel and Morel (1998)'s parameterization which is characterized by a lower $b_{\mathrm{p}} / \mathrm{TChl}-a$ value (Fig. 7a). However, based on Mie scattering calculations, it appears that $b_{\mathrm{bp}} / b_{\mathrm{p}}$ value of $2 \%$ is too high for organic particles, which are predominant in case 1 waters (Ulloha et al., 1994; Morel and Maritorena, 2001). Similar or higher $b_{\mathrm{bp}} / b_{\mathrm{p}}$ values are currently encountered in coastal areas (Sullivan et al., 2005; Loisel et al., 2007), but have never been measured in open ocean waters, at least in absence of suspended mineral particles from organic (coccolithophorids) or inorganic (atmospheric inputs) origin. The reasons of such singular $b_{\mathrm{bp}} / b_{\mathrm{p}}$ values and $b_{\mathrm{bp}}$ vs. TChl- $a$ relationship are discussed in the next section.

The fact that $b_{\mathrm{bp}}$ follows the same trend with TChl- $a$ than those described in previous studies for oligotrophic waters gives us confidence in the present data set. However, to be able to faithfully compare the present $b_{\mathrm{bp}}$ vs. TChl- $a$ relationship with the formulation by Huot et al. (2008), we 

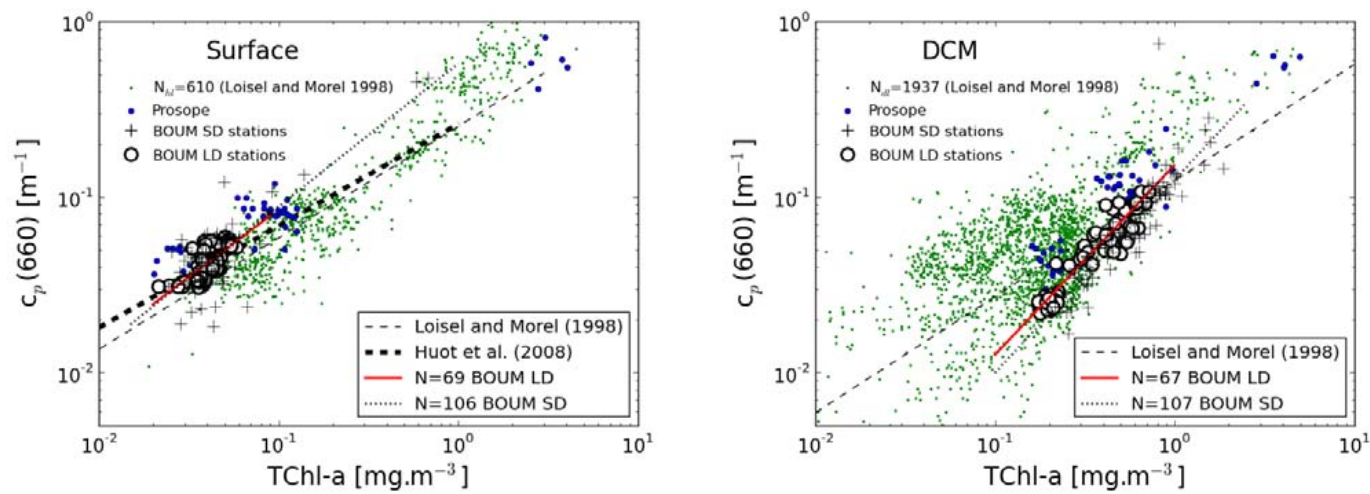

Fig. 6. Variations of the particulate attenuation coefficient, $c_{\mathrm{p}}(660)$, as a function of the TChl- $a$ concentration for (a) the surface layer, and (b) at the DCM. The data collected during BOUM at the LD and SD stations, during the PROSOPE cruise, and those gathered by Loisel and Morel (1998) are plotted as indicated. $\mathrm{N}_{\mathrm{hl}}$ and $\mathrm{N}_{\mathrm{dl}}$ represent the number of data available in the Loisel and Morel (1998) 's data set for the homogeneous and the deep layers, respectively. The results of the present and previous regression analyses are also plotted as indicated.

processed the data according to the procedure defined by Twardowski et al. (2007) also used in Huot et al. (2008). In their approach, $b_{\mathrm{bp}}$ is derived from scattering measurements performed at one scattering angle $\left(117^{\circ}\right), \beta(117)$. Then, $b_{\mathrm{bp}}$ is derived by assuming a conversion factor between $b_{\mathrm{bp}}$ and $2 \pi \beta(117)$. This conversion factor is fixed at 0.9 , according to Sulivan et al. (2005). Based on the BOUM data set, the conversion factor between $b_{\mathrm{bp}}$ and $2 \pi \beta(125)$ is 1.0086 $\left(r^{2}=0.84\right)$. This weak difference may be caused by the fact that the BOUM data set is focused on very clear waters whereas to the data set used in Sulivan et al. (2005) encompasses measurements performed in coastal areas. By applying the conversion factor used by Twardovski et al. (2007) to our measurements collected at $125^{\circ}$ we obtain higher $b_{\mathrm{bp}}$ values (by about $30 \%$ ) than those derived using the scattering measurements at three angles. Therefore, the derivation of the backscattering coefficient from a single angle, as it is done in Huot et al. (2008), would even increase the discrepancy observed with their $b_{\mathrm{bp}}$ vs. TChl- $a$ parameterization.

Moreover, other $b_{\mathrm{bp}}$ measurements were performed during the BOUM cruise using a quite different protocol (on water continuously pumped from about $9 \mathrm{~m}$ below the sea surface) and instrument (an ECO-BB3 WET Lab measuring at 3 wavelengths and at one given angle, $117^{\circ}$ ). Particulate backscattering coefficients are calculated as in Dall'Olmo et al. (2009). Only the blue and green channels can be used because the red channel showed significant drifts in the calibration coefficients measurements. Comparison between the in situ $b_{\mathrm{bp}}(650)$ values and the $b_{\mathrm{bp}}$ values obtained from the measurements performed on pumped waters at $526 \mathrm{~nm}$ shows a relatively good agreement (Fig. 7b). So, even if these two sets of $b_{\mathrm{bp}}$ measurements were acquired at different wavelengths and using different methodologies, the slight differences observed between these two data sets re-enforce our present conclusion about the backscattering anomaly, and clearly demonstrate that this is not an artifact of the measurements.

\subsection{The Mediterranean color anomaly as seen during the BOUM cruise}

\subsubsection{Ocean color anomaly}

Remote sensing reflectance measurements performed during the BOUM cruise confirm the unusual bio-optical character of the Mediterranean Sea, as previously stressed in different studies (Gitelson et al., 1996; Claustre et al., 2002; Antoine et al., 2006). The blue-to-green reflectance ratios vs. TChl- $a$ measurements depart significantly from the OC4v4 empirical formulation (O'Reilly et al., 1998) currently used to assess TChl- $a$ from the Seaviewing Wide Field-of-view Sensor (SeaWiFS) (Fig. 8). Based on the restricted BOUM radiometric data set, the OC4v4 algorithm overestimates TChl- $a$ by a factor of two, with a mean ratio of the retrieved-to-in situ TChl- $a$ using OC4v4 of $2.2 \pm 0.3$. This ratio drops to $0.9 \pm 0.2$ when using the regional algorithm developed from a data set of reflectance and chlorophyll measurements collected during the PROSOPE and AMOFRONT-2 cruises in the Mediterranean Sea (Bricaud et al., 2002). Different assumptions were proposed to explain the fact that the Mediterranean Sea is greener than TChl- $a$ alone indicates. The presence of phytoplankton cells with a high specific attenuation coefficient, such as coccolithophorids, was suggested to explain the bias observed in ultra oligotrophic waters of the eastern Mediterranean Sea (Gitelson et al., 1996). In contrast to this assumption based on a specific phytoplankton nature, the presence of submicron Saharan dust in suspension within the upper layer was advanced by Claustre et al. (2002) to explain the enhanced absorption in the blue as well as the enhanced backscattering in the green part of the visible spectrum, which tend to decrease the blue-to-green reflectance 

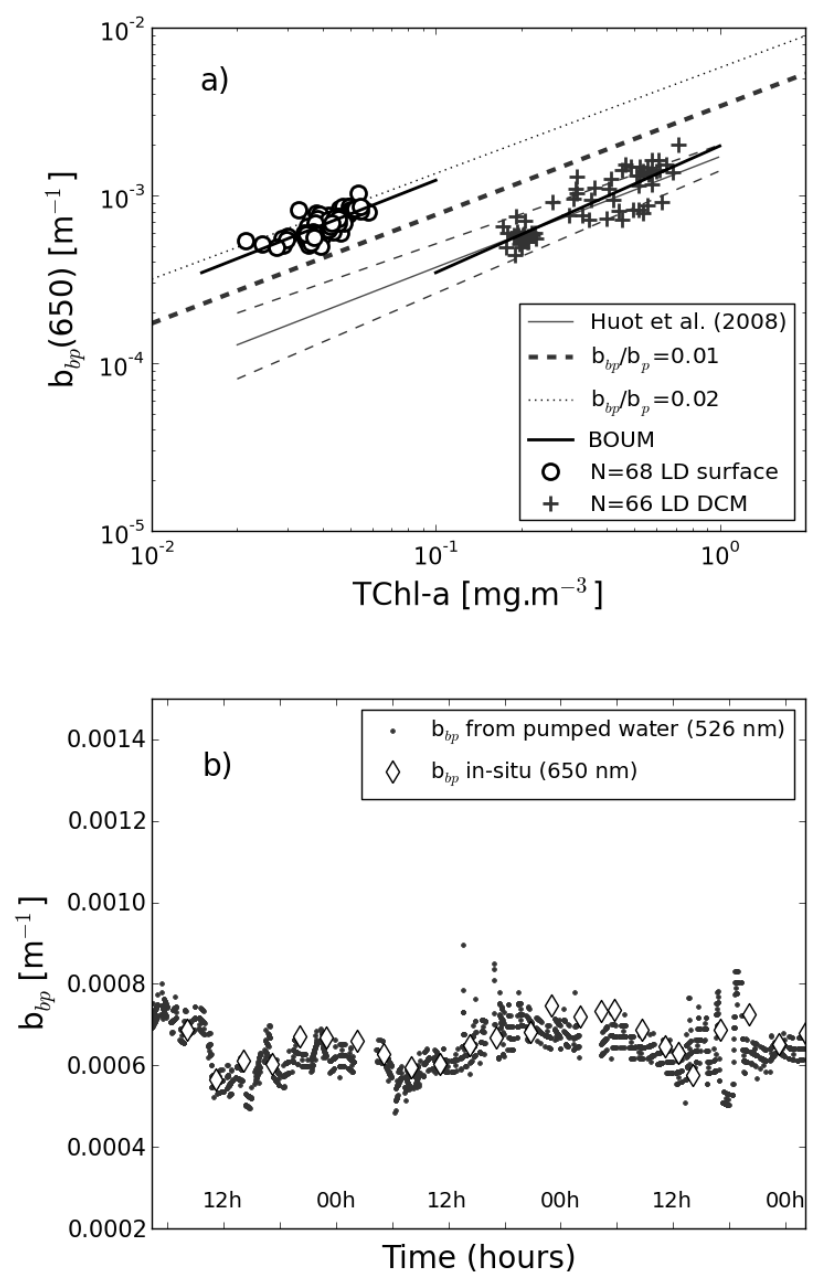

Fig. 7. (a) Variations of the particulate backscattering coefficient, $b_{\mathrm{bp}}(660)$, as a function of the TChl- $a$ concentration for the surface layer (cross), and at the DCM (circle). The two solid lines are the least squares linear fits described by the Eqs. (11) (surface layer) and (12) (DCM). The dashed and doted lines represent the semi-analytical model of Morel and Maritorena (2001), in which the mean formulation used between $b_{\mathrm{p}}$ and TChl- $a$ is replaced by the empirical formulation developed over the BOUM data set (Eq. 7), and for two different values of the backscattering ratio, $b_{\mathrm{bp}} / b_{\mathrm{p}}$, as indicated. The solid grey line represents the empirical formulation of Huot et al. (2008), and the two grey dashed lines delimit the $95 \%$ confidence interval as given in Huot et al. (2008) (their Table 1). (b) Comparison between the in situ $b_{\mathrm{bp}}(650)$ measurements and the $b_{\mathrm{bp}}(526)$ measurements performed in the wet lab on surface pumped water at station $B$.

ratio values. More recently, Morel and Gentili (2009) proposed that the TChl- $a$ overestimation by standard (global) algorithms (such as OC4v4) reflects the presence of a high CDOM background within the Mediterranean waters.

The over-estimation of TChl- $a$ by a factor of 2 using $\mathrm{OC} 4 \mathrm{v} 4$ is due to a lower blue-to-green reflectance ratio, BG, than expected (by a factor 1.4). The mean and standard

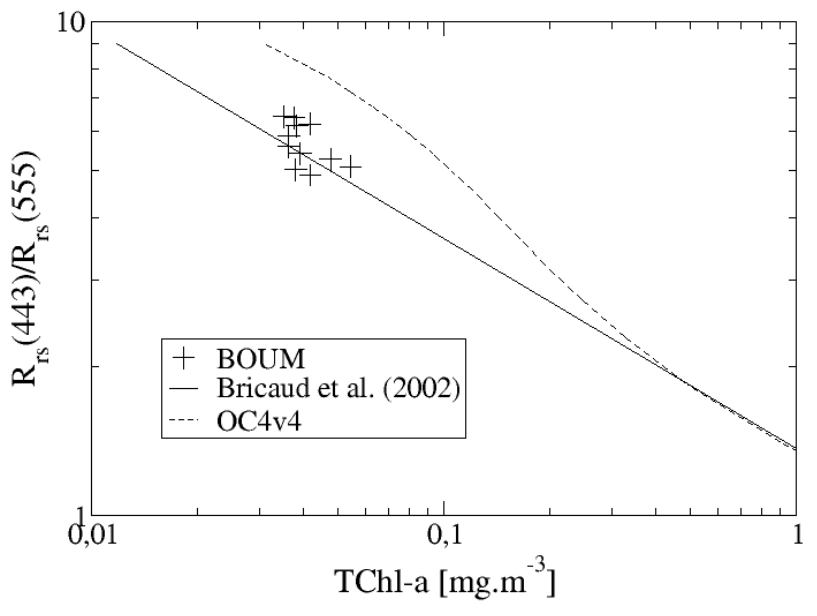

Fig. 8. Variations of the blue-to-green reflectance ratio as a function of the TChl- $a$ concentration for the BOUM data set. The dashed line represents the global NASA algorithm ("OC4v4," see O'Reilly et al., 1998), and the solid line the regional algorithm developed by Bricaud et al. (2002).

deviation of in situ BG and TChl- $a$ values are $5.66 \pm 0.67$ and $0.041 \pm 0.006 \mathrm{mg} \mathrm{m}^{-3}$, respectively. The same mean TChl- $a$ value can be obtained using OC4v4 with a BG value of 8.2 , that is 1.4 times higher than the $B G$ in situ value. The lower than expected BG value is explained by a lower than expected blue-to-green backscattering ratio, $b_{\mathrm{b}}(443) / b_{\mathrm{b}}(555)$, and/or a higher than expected blue-to-green absorption ratio, $a(555) / a(443)$. Based on standard IOPS vs. TChl- $a$ relationships the variability of BG with TChl- $a$, as driven by the empirical OC4v4 algorithm, can be reproduced to study the impact of each IOPs on the BG value. For that purpose, $b_{\mathrm{bp}}(\lambda), a_{\mathrm{p}}(\lambda)$, and $a_{\mathrm{cdom}}(\lambda)$ are modeled as a function of TChl- $a$ according to Huot et al. (2008), Bricaud et al. (1998), and Morel and Gentili (2009), respectively. For the mean TChl- $a$ value obtained from the present data set (i.e. $0.041 \mathrm{mg} \mathrm{m}^{-3}$ ) the $\mathrm{BG}$ value $(=7.9)$ calculated using these different relationships is close to the OC4v4 BG value $(=8.2)$, emphasizing that these relationships can be used in this sensitivity analysis. The impact of each IOPs measured during BOUM on the BG values is now examined by modifying the mean IOPs vs. TChl- $a$ relationships based on the BOUM data set.

\subsubsection{Absorption by particles larger than about 0.5-0.7 $\mu \mathrm{m}$}

The substitution of the mean (global) $a_{\mathrm{p}}(\lambda)$ relationships at 443 and $555 \mathrm{~nm}$ by those established from the present in situ data set in the BG parameterization only induces a very slight increase of BG. This increase is due to the lower than expected $a_{\mathrm{p}}(440)$ and $a_{\mathrm{p}}(555)$ values. Such low values are consistent with measurements performed by Bricaud et 
al. (2010) during BIOSOPE. The measured non-algal particles, $a_{\text {nap }}(440)$, values are consistent with those calculated using the mean relationship established by Bricaud et al. (2010) between $a_{\text {nap }}(440)$ and TChl- $a$ from data collected in different oceanic areas ranging from ultra-oligotrophic and eutrophic waters. For instance, for TChl $-a=0.05 \mathrm{mg} \mathrm{m}^{-3}$, $a_{\text {nap }}(440)$ is equal to 0.0023 and $0.0021 \mathrm{~m}^{-1}$ for the BOUM data set and from the Bricaud et al. (2010)'s parameterization, respectively. Therefore, absorption properties of suspended marine particles sampled during BOUM with diameters higher than $0.5-0.7 \mu \mathrm{m}$ (the assumed porosity of the GF/F filter after their precombustion) can not explain the $40 \%$ BG decrease (compared with its expected values for the same TChl- $a$ ).

\subsubsection{Absorption by small particles and colored dissolved organic matter}

Decrease in the blue-to-green reflectance ratio by a factor of 1.4 by modifying only the amount of colored dissolved organic matter would require an increase in each of the mean values of $a_{\text {cdom }}(443)$ and $a_{\text {cdom }}(555)$ as modeled by Morel and Gentili (2009) by a factor of 2.9. Unfortunately, absorption by colored dissolved organic matter, $a_{\mathrm{cdom}}(\lambda)$, and absorption by small particles with diameters between about 0.2 and $0.7 \mu \mathrm{m}, a_{\mathrm{sp}}(\lambda)$, have not been measured during the BOUM cruise. $a_{\mathrm{sp}}(\lambda)$ represents the missing part in the absorption budget, as $a_{\mathrm{p}}(\lambda)$ represents the absorption by particles retained by a filter with a nominal pore size of about $0.5-0.7 \mu \mathrm{m}$, and $a_{\mathrm{cdom}}(\lambda)$ is the absorption of the matter after filtration onto membrane filters with a $0.22 \mu \mathrm{m}$ pore size. However, $a_{\text {cdom }}(\lambda)+\mathrm{a}_{\mathrm{sp}}(\lambda)$ can be modeled by subtracting the measured particulate absorption, $a_{\mathrm{p}}(\lambda)$, and the pure sea water absorption, $a_{\mathrm{w}}(\lambda)$ (Pope and Fry, 1997), coefficients to the total absorption coefficient, $a(\lambda)$, retrieved from radiometric measurements. The remote-sensing reflectance, the average attenuation coefficient for downwelling irradiance, $K_{\mathrm{d}}(\lambda)$, between the surface and the first attenuation depth, and the solar zenith angle, are used as input parameters in the new version of the Loisel and Stramski (2000) model to assess the total absorption and backscattering coefficients. This new version directly accounts for $R_{\mathrm{rs}}$ instead of irradiance reflectance, $R\left(0^{-}\right)$, and includes more realistic $b / \mathrm{a}-b_{\mathrm{w}} / b$ combination in the different parameterizations used in the model ( $b$ and $b_{\mathrm{w}}$ are the total and pure sea water scattering coefficients, respectively). Based on a synthetic data set (IOCCG, 2006) $b_{\mathrm{bp}}(443)$ and $a-a_{\mathrm{w}}(443)$ are retrieved with a Root Mean Square error of 0.024 and 0.0022 for oligotrophic waters (Chl- $a<0.3 \mathrm{mg} \mathrm{m}^{-3}$ ). Based on the BOUM data set when $b_{\mathrm{bp}}, R_{\mathrm{rs}}$ and $K_{\mathrm{d}}$ measurements are available, the inversed-to-measured $b_{\mathrm{bp}}(650)$ ratio is $0.92 \pm 0.11$. The mean and standard deviation for the measured and inversed $b_{\mathrm{bp}}(650)$ values are $0.00074 \pm 0.00005$ and $0.00068 \pm 0.00011 \mathrm{~m}^{-1}$, respectively. Even though the number of stations is limited $(N=7)$, this result gives us a certain degree of confidence for the absorption assessment using the present model. The mean and standard deviation of $a_{\text {cdom }}(443)+\mathrm{a}_{\mathrm{sp}}(443)$ are $0.0054 \pm 0.0011 \mathrm{~m}^{-1}$ for these stations. These inversed values are slightly higher than those calculated from the mean global relationship of Morel and Gentili (2009) between $a_{\text {cdom }}$ (443) and TChl- $a$. Indeed, for the TChl- $a$ values measured at the stations considered for the inversion, the mean and standard deviation values for $a_{\text {cdom }}(443)$ are $0.0042 \pm 0.0004 \mathrm{~m}^{-1}$. The inversed values are therefore greater by a factor of 1.29 than the averaged values, which is far from the factor 2.9 that should be considered to explain the BG anomaly with only absorption by $\mathrm{CDOM}$ and submicron particles. Note that by taking into account an error of $40 \%$ in the $a_{\mathrm{cdom}}(443)+a_{\mathrm{sp}}(443)$ retrieval would provide values greater by a factor of 1.8 than the averaged values.

\subsubsection{The scattering and backscattering anomalies}

The present in situ data set reveals that both surface $c_{\mathrm{p}}{ }^{*}$ and $b_{\mathrm{bp}} *$ are higher than expected using standard relationships developed for open ocean waters (Loisel and Morel, 1998; Huot et al., 2008). Our high $c_{\mathrm{p}}{ }^{*}$ values are consistent with the findings of Gitelson et al. (1996) and Claustre et al. (2002). For instance, Claustre et al. (2002) have shown that the particulate scattering coefficients measured in the Ionian Sea (eastern basin of the Mediterranean sea) were higher by a factor of 2.4 than the ones modeled according to Loisel and Morel (1998) using their data Subsects. 2 and 3. With the BOUM data set this overestimation reaches a factor of 1.4. The discrepancy between the measured and modeled $c_{\mathrm{p}}$, is even more pronounced for $b_{\mathrm{bp}}$ in the ultra oligotrophic parts of the Mediterranean Sea sampled during the BOUM cruise. This is the first time that such large $b_{\mathrm{bp}} *$ values are reported in ultra oligotrophic environments, as only scattering or attenuation measurements were performed in the previously cited studies (mainly due to the relatively recent commercial availability of appropriate instrumentation). While recent studies stressed that higher than averaged $b_{\mathrm{bp}} *$ values lead to an over-estimation of TChl- $a$ by standard global algorithms using blue-to-green reflectance ratios (Brown et al., 2008; Loisel et al., 2010), the relevant driving processes are not totally understood. Based on the present data set and for TChl$a=0.041 \mathrm{mg} \mathrm{m}^{-3}, b_{\mathrm{bp}}(650)$ is greater by a factor of 3.26 compared to the averaged value of Huot et al. (2008). The spectral values of $b_{\mathrm{bp}}(\lambda)$ are computed using three methods to assess the effect of $b_{\mathrm{b}}(443) / b_{\mathrm{b}}(555)$ on BG. First, the spectral dependencies as established by Huot et al. (2008) from their different parameterizations between $b_{\mathrm{bp}}(\lambda)$ and TChl- $a$ are used to assess $b_{\mathrm{bp}}(443)$ and $b_{\mathrm{bp}}(555)$ from the $b_{\mathrm{bp}}(650)$ measurements performed during the BOUM cruise. In this configuration the blue to green reflectance ratio decreases by a factor of 1.10 compared to its mean expected value for TChl- $a=0.041 \mathrm{mg} \mathrm{m}^{-3}$. Second, $b_{\mathrm{bp}}(555)$ is equal to the $b_{\mathrm{bp}}(443)$ value as calculated in the first configuration. This 
configuration, which accounts for the presence of absorbing particles in the blue being responsible for the decreasing $b_{\mathrm{bp}}(443)$ value through the absorbing depressing effect, explains more than half of the BG anomaly. Indeed, the BG decreases by a factor of 1.33 compared with the factor 1.4. At last, $b_{\mathrm{bp}}(443)$ and $b_{\mathrm{bp}}(555)$ are calculated from $b_{\mathrm{bp}}(650)$ assuming a spectral dependency of $\lambda^{-1}$ and $\lambda^{-3.5}$, respectively. Note that such high $b_{\mathrm{bp}}$ spectral dependency has already been reported in the Mediterranean Sea in summer (Antoine et al., 2011). This configuration, in which $b_{\mathrm{bp}}(555)$ is slightly higher than $b_{\mathrm{bp}}(443)$ (by a factor 1.20), almost fully explains the 1.4 decreasing of the blue-to-green ratio. The two last scenarios in terms of $b_{\mathrm{bp}}$ spectral shapes account for the fact that these particles should strongly backscatter light in the green part of the spectrum due to (i) their specific properties and (ii) the absorbing depressing effect in the backscattering spectrum, which reduce the number of backscattered photons in the blue. The spectral variability of $b_{\mathrm{bp}}$ calculated from the scattering measurements performed in the blue $(470 \mathrm{~nm})$ and in the green $(526 \mathrm{~nm})$ parts of the spectrum on pumped-water, as described in the Sect. 3.2, emphasizes that the second scenario is the more reliable one. Indeed, the $b_{\mathrm{bp}}(470) / b_{\mathrm{bp}}(526)$ ratio is $1.04 \pm 0.06$ for stations where the blue-to-green reflectance anomalies have been reported. This ratio is significantly lower that the one measured in the most oligotrophic part of the Atlantic ocean during the AMT19 cruise $\left(b_{\mathrm{bp}}(470) / b_{\mathrm{bp}}(526) \approx 1.2\right)$ using the same measurement protocol (Dall'Olmo, personal communication, 2011). This feature again stress the peculiar bio-optical character of these Mediterranean waters sampled.

Based on the different scenarios of specific IOPs examined above, one may assume that the presence of highly refractive suspended marine particles with diameter lower than $0.5-0.7 \mu \mathrm{m}$ in the surface layer of the Mediterranean Sea could explain most of the observed blue-to-green reflectance anomalies. The vertical variability of the factor appearing in Eq. (11) (0.00573) and (12) (0.00197) emphasizes that the overestimation of $b_{\mathrm{bp}}$, compared to its mean expected value, is restricted to a surface layer of about $40 \mathrm{~m}$ deep (Fig. 9). In the same way, the higher determination coefficient found between $c_{\mathrm{p}}$ or $b_{\mathrm{bp}}$ and TChl- $a$ at the DCM compared to their surface value stress that the variability in both $b_{\mathrm{bp}}$ and $c_{\mathrm{p}}$ is more tightly related to that of TChl- $a$ at the DCM (Eqs. 7, 9, 11, and 12). The presence of non-pigmented particles (in terms of TChl- $a$ ) at the surface could explain part of this difference. Therefore, the combination of the inversed $a_{\mathrm{cdom}}(\lambda)+a_{\mathrm{sp}}(\lambda)$ values, which decreases BG by a factor of 1.08 , and the $b_{\mathrm{bp}}(\lambda)$ values calculated using the second scenario, explains the full blue-to-green reflectance ratio anomaly.

\subsubsection{Origin of the submicrometer particles}

Even though Mie calculations should be used with caution for the interpretation of $b_{\mathrm{bp}}$ (Stramski et al., 2004), it

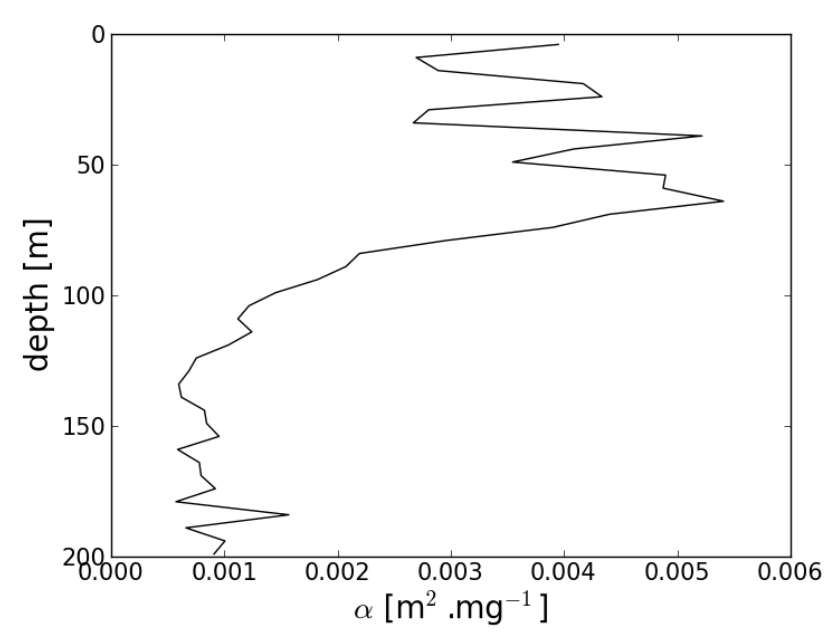

Fig. 9. Vertical evolution of the coefficient $\alpha\left(b_{\mathrm{bp}}=\alpha\right.$ TChl- $\left.a^{\beta}\right)$ calculated from a regression analysis performed at different depths between the $b_{\mathrm{bp}}$ and TChl- $a$ data values measured at the three long duration stations.

provides some insights if one considers particles as homogeneous spheres. In this context, the higher-than-expected $b_{\mathrm{bp}}$ surface values for a given TChl- $a$ may be caused by a much greater concentration of small organic living or non-living particles compared to large particles, or/and by the presence of highly refractive particles. Indeed, hyperbolic particle size distribution with a high slope value, and particles with high refractive index both explain the high $b_{\mathrm{bp}} / b_{\mathrm{p}}$ values reported here (see Fig. 9 in Twardowski et al., 2001). Based on these theoretical considerations, the following different types of particles could explain the high $b_{\mathrm{bp}} *$ and $b_{\mathrm{bp}} / c_{\mathrm{p}}$ values in the studied area: a high concentration of submicron non-living or living organic particles, highly refractive submicron Saharan dust, and highly refractive coccolithophores. Based on the fact that high $b_{\mathrm{bp}} *$ values are found at the three long duration stations which are located in the eastern, central and western part of the Mediterranean Sea, and that these particles should be in the submicron size range with therefore a negligible sinking velocity, coccolithophores are not the most plausible candidates to explain the BG anomaly. Picoparticles, amongst which picodetritus have a lower water content and a higher refractive index than phytoplankton cells, may appear in high concentrations as shown in Loisel et al. (2006) in the ultra-oligotrophic waters of the south Pacific gyre. However, no $b_{\mathrm{bp}}$ and BG anomalies were observed during BIOSOPE where very steep slopes of the particle size distribution in the submicrometer range were measured. In contrast to the two previous types of particles, strong evidence indicates that highly refractive particles from Saharan origin could explain the BG anomalies as already advanced by Claustre et al. (2002). Firstly, vertical profiles of lithogenic silica, LSi, a desert dust tracer (Betzer et al., 1988), exhibit high surface concentration for each LD stations (Fig. 10a). Besides, 
the LSi concentration values are generally much higher, up to a factor of 5, in the surface layer compared to deeper waters (Fig. 10a). Lithogenic silica data in the open ocean are very scarce, as LSi is often measured only in coastal environments as a way to correct BSi measurements from lithogenic interference (Raguenau and Tréguer, 1994; Ragueneau et al, 2005). However, LSi concentrations for open oligotrophic areas are usually close to $\sim 0.01 \mu \mathrm{mol} \mathrm{L}-1$ at the surface level (Leblanc, personal communication from unpublished data, Adjou et al., 2011). Concentrations $>0.01 \mu \mathrm{mol} \mathrm{L}^{-1}$ are usually clearly associated with either: samples close to the sea floor and containing suspended sediment, samples collected at coastal sites or near river mouth, or dust deposition events. Unfortunately, to our knowledge, there are no data comparing dust collected during a dust storm and in situ lithogenic silica concentrations. However there is no doubt that LSi increases in the water column trace either sediment or aerosol presence in the form of aluminosilicates eroded from the earth crust. Hence, in open waters far from the coast and with deep bathymetry, LSi increases can only trace either lateral advection of sediment particle with a strong current, or aerosol deposition from the atmosphere which is the most likely explanation in our present study. Secondly, OMI daily products of absorbing aerosol index (http://toms.gsfc.nasa.gov/aerosols/aerosols_v8.html) reveal that Saharan dust events occurred before and during the cruise (Fig. 10b). Note however that the satellite observation of Saharan dust events does not necessarily indicate that a deposition in the Mediterranean Sea occurred. Finally, a wet dust deposition event has been observed during the transect between the short duration station 17 and the long duration station A (Ternon et al., 2011). Even if most of the BG anomaly seems to be related to the presence of submicrometer and highly refractive particles, complete field measurements of the different parameters $\left(R_{\mathrm{rs}}(\lambda), b_{\mathrm{bp}}(\lambda)\right.$, $\left(a_{\text {cdom }}+a_{\mathrm{sp}}\right)(\lambda)$, TChl- $a$, LSi, coccolithophores identification, and particle size distribution), should however be performed in the future to strengthen this hypothesis. Note however that measurement of particles size distribution in the submicrometer size range is still very challenging (Loisel et al., 2006).

\subsection{Diel cycle in $c_{\mathrm{p}}$ and $b_{\mathrm{bp}}$ and associated biogeochemical applications}

\subsection{1 $\quad c_{\mathrm{p}}$ and $b_{\mathrm{bp}}$ diel cycles}

The $c_{\mathrm{p}}$ and $b_{\mathrm{bp}}$ time series recorded during the BOUM cruise show clear daily oscillations for the two long stations A and B (Fig. 11), while no distinct daily patterns were detected at station $\mathrm{C}$ neither for the biological parameters (e.g. the TChl- $a$ ) or optical parameters. The absence of diurnal cycle at station $\mathrm{C}$ could be explained by a mixed situation in terms of phytoplankton composition. In the Provencal Basin (station $\mathrm{A}$ ), significant diurnal variations in $c_{\mathrm{p}}$ and $b_{\mathrm{bp}}$ are a)
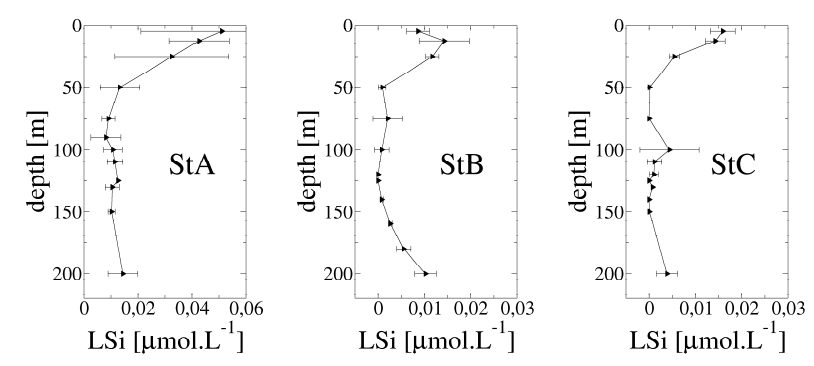

b)

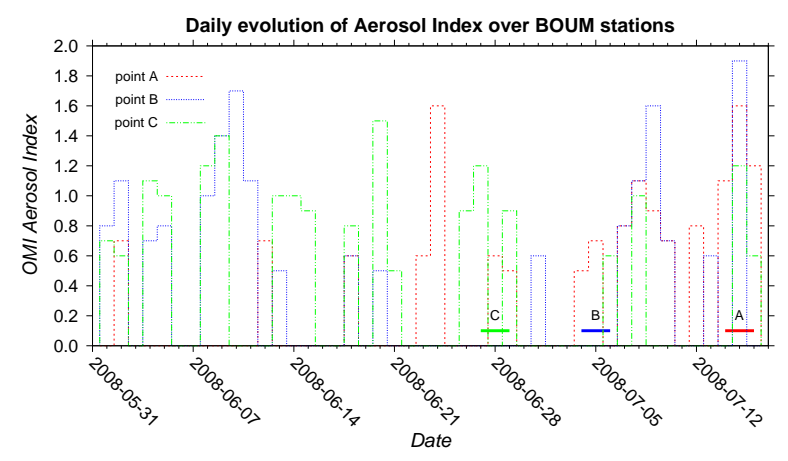

Fig. 10. (a) Mean vertical profiles of lithogenic silica, LSi, performed at each Long duration station. Horizontal bars represent the standard deviation. (b) Temporal evolution of the OMI daily products of absorbing aerosol index.

mostly observed around the DCM (80-90 m). Conversely, in the Ionian Sea (station B) $c_{\mathrm{p}}$ and $b_{\mathrm{bp}}$ day-night cycles can be detected from the water column surface down to the upper TChl- $a$ maximum $(\sim 75 \mathrm{~m})$ while the latter parameters remained relatively stable in time within the second DCM located below the euphotic depth $(140 \mathrm{~m}) . c_{\mathrm{p}}$ and $b_{\mathrm{bp}}$ daily oscillations appear to be slightly decayed in time for both sites. This feature is represented clearly in Fig. 12, which shows the time series of $c_{\mathrm{p}}$ and $b_{\mathrm{bp}}$ values integrated from the surface to the depth corresponding to 1.5 Zeu (i.e. 123 and $155 \mathrm{~m}$ for $\mathrm{A}$ and $\mathrm{B}$ respectively). For both A and B stations $c_{\mathrm{p}}$ is minimal around sunrise and maximal around sunset (excepted for Day 2 at station A) in agreement with previous observations performed for various oligotrophic and mesotrophic ecosystems (Siegel et al., 1989, Claustre et al., $1999,2008)$. Integrated $b_{\text {bp }}$ minimum values are usually synchronized to $c_{\mathrm{p}}$ whereas maximum $b_{\mathrm{bp}}$ are often reached 3 to $6 \mathrm{~h}$ later than those for $c_{\mathrm{p}}$ (Days 1 and 2 for both stations). The mean integrated $c_{\mathrm{p}}$ and $b_{\mathrm{bp}}$ daily values levels remain stable over the 3 days of the long time stations excepted for the station $\mathrm{B}$ where $c_{\mathrm{p}}$ values tend to decrease by $12 \%$ over the duration of the experiment.

The amplitude of daytime variations experienced by $c_{\mathrm{p}}$ reaches up to 19 and $14 \%\left(\left[\mathrm{c}_{\mathrm{pmax}}-\mathrm{c}_{\mathrm{pmin}}\right] / \mathrm{c}_{\mathrm{pmin}} .100\right)$ in average for station $\mathrm{A}$ and $\mathrm{B}$, respectively. This is in the range of the value previously reported in the eastern Ionian sea 

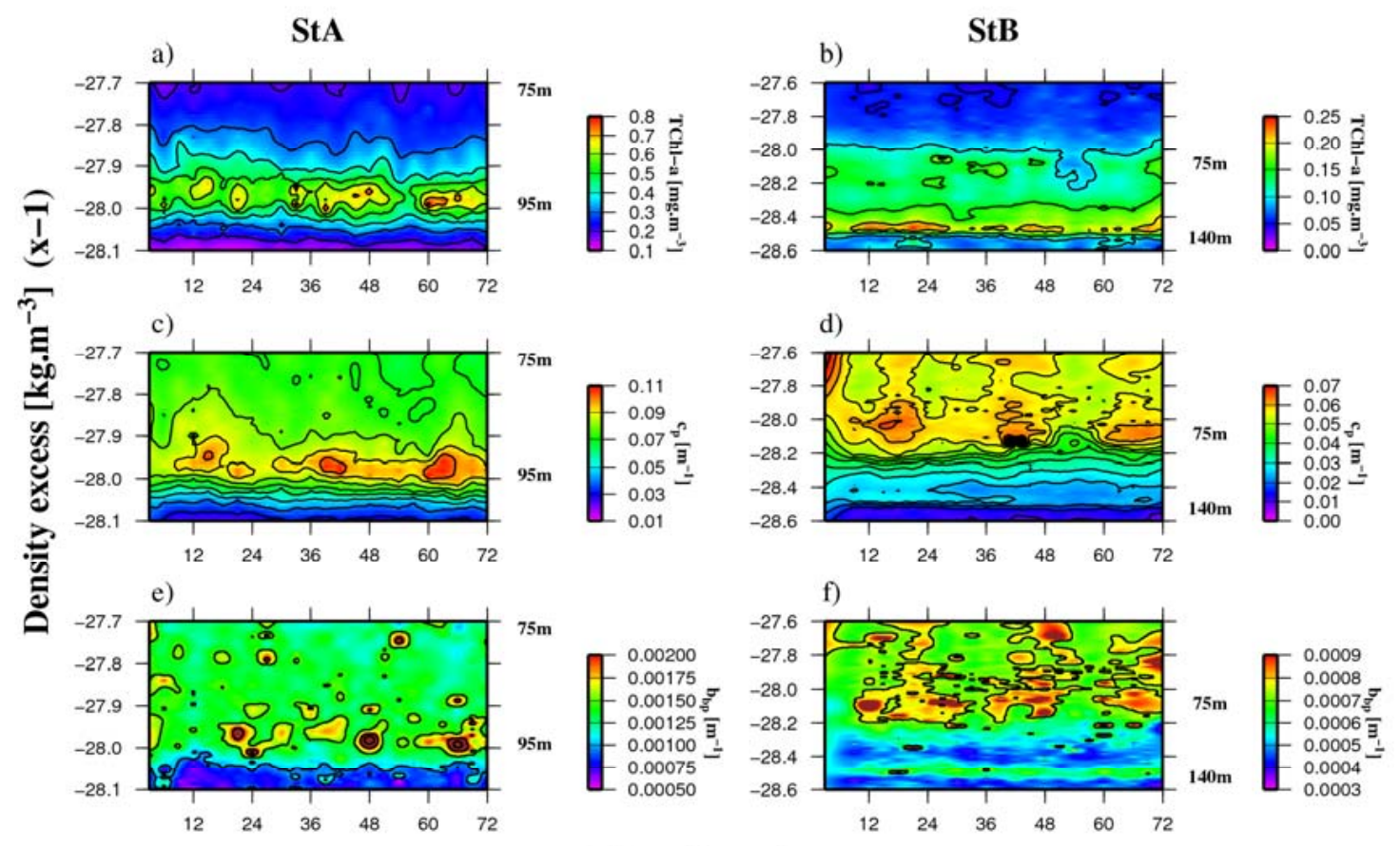

Time [hour]

Fig. 11. Contour plot showing the vertical and temporal evolution of the chlorophyll fluorescence (a, b) of the particle attenuation coefficient, $c_{\mathrm{p}},\left(\mathrm{m}^{-1}\right),(\mathbf{c}, \mathbf{d})$ and of the particle backscattering coefficient, $b_{\mathrm{bp}},\left(\mathrm{m}^{-1}\right)(\mathbf{e}, \mathbf{f})$ at stations $\mathrm{A}$ and $\mathrm{B}$ respectively. The vertical dimension is represented in terms of density in order to remove the effects of internal waves throughout the water column.

(5-21\%, Oubelkheir and Sciandra, 2008) but remains lower than those documented for other areas (e.g. equatorial and tropical Pacific 25-70\%, Claustre et al., 1999; Durand and Olson, 1996; Gardner et al, 1995). Such diel changes in $c_{\mathrm{p}}$ correspond to mean diurnal rate of variation $\left(\mu_{\mathrm{cp}}\right.$, in $\left.\mathrm{d}^{-1}\right)$ of 0.32 and $0.37 \mathrm{~d}^{-1}$ in stations $\mathrm{A}$ and $\mathrm{B}$, respectively, estimated using the formulation proposed by Cullen et al. (1992):

$\mu_{\mathrm{cp}}=24 /\left(t_{2}-t_{1}\right) \ln \left(c_{p 2} / c_{p 1}\right)$

where $t_{1}$ and $t_{2}$ correspond to the actual minimum and maximum daily $c_{\mathrm{p}}$ values. These rates agree with those reported by several authors for oligotrophic conditions (Gernez et al., 2011 and references therein). Note that the latter $\mu_{\mathrm{cp}}$ falls to $0.2 \mathrm{~d}^{-1}$, for both $\mathrm{A}$ and $\mathrm{B}$ when $\mu_{\mathrm{cp}}$ is calculated using $c_{\mathrm{p}}$ sunset and sunrise values as recommended by the previous authors emphasizing that the actual extreme $c_{\mathrm{p}}$ values we measured are not perfectly synchronized to the extreme variation in the light environment. Such time shift of the $c_{\mathrm{p}}$ extreme values from sunset and sunrise have already been noticed (Gernez et al., 2011; Oubelkheir and Sciandra, 2008).

Relative daily increase experienced by $b_{\mathrm{bp}}$ value is slightly lower than those for $c_{\mathrm{p}}$ reaching mean values of 14 and $13 \%$ for stations $\mathrm{A}$ and $\mathrm{B}$, respectively. In average, the decrease in $c_{\mathrm{p}}$ ( -20 and $-17 \%$ for $\mathrm{A}$ and $\mathrm{B}$ respectively) and $b_{\mathrm{bp}}(-13 \%$ for $\mathrm{A}$ and $\mathrm{B})$ during nighttime almost balance the daytime increase of the latter parameters, even though a strong day to day variability is observed for both $c_{\mathrm{p}}$ and $b_{\mathrm{bp}}$ (Fig. 12). The diurnal rates of variation for $b_{\mathrm{bp}}\left(\mu_{\mathrm{bbp}}, \mathrm{d}^{-1}\right)$ are slightly lower than the corresponding $\mu_{\mathrm{cp}}$ values $(0.27$ and $0.26 \mathrm{~d}^{-1}$ for stations $\mathrm{A}$ and $\mathrm{B}$ respectively).

In addition to these differences in the magnitude of the diel cycles, relevant discrepancies have been observed between the timing of the diel variations associated with $b_{\mathrm{bp}}$ and $c_{\mathrm{p}}$ within the different sites. Moreover, a marked day-today variation in the extent of the $c_{\mathrm{p}}$ diel oscillations has also been noticed. However, we assume that a clear explanation of these discrepancies cannot be assessed from the present dataset, which only covers a limited number of diel cycles and emphasizes the need of longer time series. Indeed, the latter features reflect heterogeneities in the sensitivity of the latter optical parameters to spatial and temporal changes in the structure of the particle assemblage, which is diversely composed of various types of phytoplankton, heterotrophs and detritus, as well as in changes regarding the properties of the individual particles (including abundance, size, refractive index, shape or internal structure). As a matter of fact, particle attenuation and backscattering coefficients depend on the numerical concentrations of all particles in a given water volume and the particles geometric cross section and efficiency factor for attenuation and backscattering (Bricaud and Morel 1986; Morel and Bricaud 1986). A quantitative estimation of the factors driving the diel dynamics of 

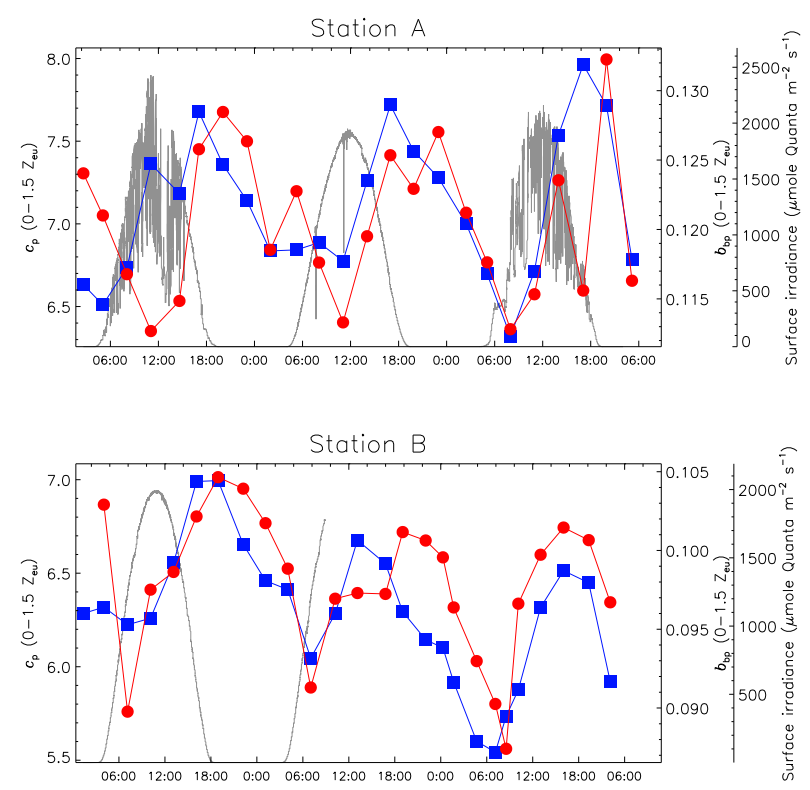

Fig. 12. Temporal evolution of the vertically integrated $\left(0-1.5 \mathrm{Z}_{\mathrm{eu}}\right)$ particle backscattering (red circles) and attenuation (blue squares) coefficients at stations A and B, respectively. The grey line represents the evolution of the surface irradiance over the same period of time ( $\mu$ mole Quanta $\mathrm{m}^{-2} \mathrm{~s}^{-1}$ ).

$b_{\mathrm{bp}}$ and $c_{\mathrm{p}}$ needs a relevant description of each of the latter parameters appearing for the various types of particles sampled. These required parameters have not been acquired during the BOUM cruise and remain very difficult to estimate from in situ measurements (Claustre et al., 2000; Boss et al., 2001; Oubelkheir et al., 2005).

The diurnal increase in $c_{\mathrm{p}}$ can diversely be related to phytoplankton photosynthetic production, diurnal variations in heterotrophic bacteria abundance and detrital matter concentration (Stramski and Reynolds, 1993; Stramski, 1999; Claustre et al., 2008; Oubelkheir and Sciandra, 2008). Among those factors, daily changes in phytoplankton properties (i.e. size and refractive index) induced by the accumulation of carbon within the phytoplankton cells associated with photosynthetic processes have been often considered as the main driving factors for $c_{\mathrm{p}}$ diel variations by several authors (e.g. Stramski and Reynolds, 1993; Stramski, 1999; Durand and Olson, 1998; Binder and Durand, 2002). For instance, numerous laboratory measurements have shown that the diel variations of $c_{\mathrm{p}}$ are mainly caused by variation of the scattering cross section of phytoplankton cells, driven by refractive index (i.e. changes in intracellular carbon concentration) and cell size, rather than by the variation of their concentration (Stramski and Reynolds, 1993). However, Oubelkheir and Sciandra (2008) have shown from in situ measurements that while $c_{\mathrm{p}}$ undergoes a daily percent increase ranging between $5 \%$ and $21 \%$, the concentration of particles increases by $6 \%$ to $8 \%$. Controversial results by Oubelkheir and Sciandra
(2008) have also emphasized the predominant impact of the cell abundance of heterotrophic bacteria on $c_{\mathrm{p}}$ daily variability in the eastern Ionian Sea. Situations observed at stations $\mathrm{A}$ and $\mathrm{B}$ seem to be more contrasted. Indeed, in the Provencal basin (station A), the strong $c_{\mathrm{p}}$ and $b_{\mathrm{bp}}$ daily oscillations found in the DCM $(90 \mathrm{~m})$ are positively correlated with the temporal evolution of cell bacteria abundance ( $\mathrm{r}$ Pearson $=0.5$ and 0.6 , respectively). In addition, significant correlations are also found between $c_{\mathrm{p}}$ and $b_{\mathrm{bp}}$ and picoeukaryotes, Synecochoccus and Prochlorococcus abundances $(r-P e a r s o n=[0.5-0.8])$ however it concerns mostly depths corresponding to the deep limit of the DCM (100$110 \mathrm{~m})$. At station $\mathrm{B}$, weaker positive correlations are also found between $b_{\mathrm{bp}}$ and phytoplankton and $b_{\mathrm{bp}}$ and bacterioplankton abundances $(r-P e a r s o n=[0.4-0.6])$ essentially in the upper part of the water column while significant correlations for $c_{\mathrm{p}}$ are mostly found for the deep samples (below $90 \mathrm{~m}$ depth). The impact of the detritus dynamics on $c_{\mathrm{p}}$ and $b_{\mathrm{bp}}$ diel variability seems to be relatively limited as emphasized by the absence of significant diel variations in the detrital matter absorption coefficient, $a_{\mathrm{det}}$, for both stations $\mathrm{A}$ and B (not shown). This is consistent with findings by DuRand and Olson (1996) who have shown that non-algal material is relatively constant over a daily scale. Such correlations are however not sufficient to assess the actual impact of each of the latter contributors to the diel variation of particulate matter attenuation and backscattering properties due to the actual lack of knowledge regarding the specific optical properties associated especially with heterotrophic bacteria and detritus.

The lower magnitude of the diel variations for $b_{\mathrm{bp}}$ might be related to the high sensitivity of $b_{\mathrm{bp}}$ to changes in the small particle abundance which represents only a limited part of the particulate matter assemblage sampled in the studied areas (assuming that detritus do not present a significant diel cycle). As a matter of fact, diel variations in the particulate matter associated with large phytoplankton cells, whose relative contribution has been found to be relatively high in the water masses sampled during the BOUM experiment (high contribution of nano-phytoplankton, relatively high size index), might therefore induce stronger diurnal changes in $c_{\mathrm{p}}$ than in $b_{\mathrm{bp}}$ values. Similarly, differences observed in the timing of $c_{\mathrm{p}}$ and $b_{\mathrm{bp}}$ diel maxima might be related to an increase in the small sized phytoplankton cells induced by cell division processes during nighttime as previously emphasized from in situ studies (Vaulot and Marie, 1999; Oubelkheir and Sciandra, 2008; Slade et al., 2010). Again the latter pattern might have a greater impact on $b_{\mathrm{bp}}$ than on $c_{\mathrm{p}}$ values which is only moderately impacted by cellular division processes (12-20\% of the $c_{\mathrm{p}}$ variations according to Claustre et al, 1999 and DuRand and Olson, 1996). As a matter of fact, daily oscillations found at the station A for the ratio between vertically integrated $b_{\mathrm{bp}}$ and $c_{\mathrm{p}}$ values (a proxy for $b_{\mathrm{bp}} / b_{\mathrm{p}}$ ratio, not shown), being maximal during nighttime and varying by about $20 \%$ relative to its minimal 
level, emphasize the presence of relevant diel changes in the particle size distribution (and refractive index) over the investigated time period. It should be noticed that the latter processes might also occur during daytime (Chilshom and Costallo, 1980) and might shift between the different phytoplankton groups that make the phytoplankton community as highlighted by Vaulot and Marie (1999) for the various autotrophic picoplankton groups in the equatorial Pacific. Absence of correlation between Prochlorococcus, Synecochoccus, picoeukaryotes and bacteria abundances, as detected from cytometry counting (Mauriac, personnal communication, 2011), are also found within the water masses sampled in stations A and B, however the present time series are not long enough to provide any clear evidence explaining the discrepancies existing between $b_{\mathrm{bp}}$ and $c_{\mathrm{p}}$ diel variations.

\subsubsection{Biogeochemical applications}

The strong correlation between $c_{\mathrm{p}}$ and POC concentration (Loisel and Morel, 1998; Claustre et al., 2008) suggests that the diel variation in $c_{\mathrm{p}}$ significantly reflects the different gain and loss terms involved in the carbon budget within the upper part of the ocean waters. Considering this feature, several authors (Claustre et al., 2008 and references therein) have proposed to infer biogeochemical fluxes (including phytoplankton growth rates, production and community production) from $c_{\mathrm{p}}$ measurements which present the interest to be non-intrusive and much more easily acquired than the classical biogeochemical approaches. Importantly, the same assumption can be performed for $b_{\mathrm{bp}}$ and our results show clear diel cycles in particle backscattering properties, which emphasize the potential for $b_{\mathrm{bp}}$ values to be also used as a proxy for estimating upper ocean biogeochemical rates. This last feature is of particular interest since $b_{\mathrm{bp}}$ can be inferred from satellite remote sensing measurements now with satisfying accuracy (Loisel et al., 2001; Dupouy et al., 2003; IOCCG, 2006).

When phytoplankton dynamics represents the major contributor to the diel variability in $c_{\mathrm{p}}$, they can be used to assess phytoplankton growth and production rates (Binder and Durand 2002). In the present study, this assumption does not hold since bacterial abundance variability has also been shown to significantly impact $c_{\mathrm{p}}$ and $b_{\mathrm{bp}}$ diel cycles both in the Ionian Sea and in the Provencal basin. However, assuming that the dynamics of the other living components of the particulate assemblage (i.e. heterotrophic bacteria, flagellates) are positively correlated to the dynamics of the phytoplankton photosynthetic processes $c_{\mathrm{p}}$ and $b_{\mathrm{bp}}$ data can be thus used to assess community production loss and gain terms.

Daily changes in $c_{\mathrm{p}}$ and $b_{\mathrm{bp}}$ have to be converted first into $\mathrm{POC}\left(\mathrm{POC}_{\mathrm{cp}}\right.$ and $\mathrm{POC}_{\mathrm{bbp}}$, respectively) concentrations. As reported in the Sect. $3.2 c_{\mathrm{p}}$-POC relationships significantly differ according the layer of the water column considered. However, in the context of biogeochemical applications vertically integrated $\mathrm{POC}_{\mathrm{cp}}$ should be considered. Therefore, $c_{\mathrm{p}}$ has been scaled into POC concentration using the following relationship between integreted (and not discret) data:

$$
\begin{aligned}
& \int_{0}^{1.5 Z e u} \operatorname{POC}(z) d z=286 \int_{0}^{1.5 Z \mathrm{Zu}} c_{p}(z) d z+3163, \\
& R^{2}=0.42, N=34
\end{aligned}
$$

During the BOUM experiment, very few coincidental measurements of $b_{\mathrm{bp}}$ and $\mathrm{POC}$ have been performed precluding a direct estimation of POC content from $b_{\mathrm{bp}}$ values. $b_{\mathrm{bp}}$ values have been therefore scaled into POC by combining the relationship $c_{\mathrm{p}}=47.8 . b_{\mathrm{bp}}+1.46\left(r^{2}=0.86, n=69 p<0.001\right)$ with the integrated $c_{\mathrm{p}}$-POC scaling equation reported previously (Eq. 16).

The daytime increase (i.e. the difference between the actual minimal and maximal POC values) in POC derived from optical measurements gives an estimate of the Gross Community Production rate (GCP, Claustre et al., 2008, see Sect. 2.2). GCP estimated from $\mathrm{POC}_{\mathrm{cp}}$ and $\mathrm{POC}_{\mathrm{bbp}}$ are an average of $651( \pm 27)$ and $512( \pm 100) \mathrm{mg} \mathrm{C} \mathrm{m}^{-2} \mathrm{~d}^{-1}$ and 638 $( \pm 131)$ and $351( \pm 90) \mathrm{mg} \mathrm{C} \mathrm{m}^{-2} \mathrm{~d}^{-1}$ for the stations $\mathrm{A}$ and $\mathrm{B}$, respectively. The apparent discrepancies between GCP derived from particle attenuation and backscattering properties (differences of a factor 1.3 and 1.8 between the two methods for the stations A and B, respectively) mainly reflect the differences existing in the magnitude of the diel variations of the latter optical parameters but also differences in the POC scaling factors used. The GCP rates estimated from optical proxies should be compared to the GCP rates measured using classical biogeochemical approaches $\left(\mathrm{GCP}_{\text {meas }}=\right.$ primary production + bacterial production). However, a direct comparison with in situ primary production measurements is made difficult since ${ }^{14} \mathrm{C}$ based primary production is neither a gross production rate nor a net production rate. As a matter of fact, Moutin et al. (1999) have proposed a model computing gross primary production rates as: GPP $=1.72$ $A_{N}$ where $A_{N}$ is the daily primary production ( $24 \mathrm{~h}$ dawnto-dawn) rate measured with the ${ }^{14} \mathrm{C}$ method. Considering the rescaled GPP, the sum of the bacterial and phytoplankton primary productions reaches 506 and $283 \mathrm{mg} \mathrm{C} \mathrm{m}^{-2} \mathrm{~d}^{-1}$ for stations $\mathrm{A}$ and $\mathrm{B}$, respectively. $\mathrm{POC}_{\mathrm{bbp}}$ values provide, therefore, GCP estimates narrower than those derived from classical measurements (factor of 1.01 and 1.24 between $\mathrm{GCP}_{\mathrm{bbp}}$ and $\mathrm{GCP}_{\text {meas }}$ ) while $\mathrm{POC}_{\mathrm{cp}}$ tends to induce a greater overestimation of the actual GCP values (by a factor of 1.28 and 2.25 for stations $\mathrm{A}$ and $\mathrm{B}$, respectively). The latter feature might translate that $c_{\mathrm{p}}$ and $b_{\mathrm{bp}}$ measurements focus on different fractions of the particulate matter stock, $b_{\mathrm{bp}}$ providing a better description of the smaller sized particles (in the frame of the Mie scattering theory), which may reflect only partially the diel variations of the POC associated with the whole particle pool. 
Previous studies have reported strong overestimation of optically derived GCP when compared with biogeochemical estimates. Claustre et al. (2008) in the south Pacific Gyre region have for instance documented $\mathrm{GCP}_{\mathrm{cp}}$ greater by a factor of up to 7 than that derived from using ${ }^{14} \mathrm{C}$ labelling. Such overestimation has been related to a misestimation of the actual production rates made by the classical approaches for very deep samples (below the Zeu) which are difficult to maintain under dim light during laboratory measurements (Claustre et al., 2008). This feature might also explain the differences observed in this study. Importantly, our results stress the crucial need of $c_{\mathrm{p}}$ (and $b_{\mathrm{bp}}$ ) to POC conversion factors that reflect the whole water column instead of conversion factors associated with a specific depth which might not be representative of the entire water column and induce a bias in the POC and therefore GCP estimates. Indeed, when using for instance $c_{\mathrm{p}}$ to POC conversion factors derived from the surface samples (Eq. 12), GCP is greatly overestimated by the optical approaches by a factor of 3 to 4 for both stations A and B. Application of this vertical integrated conversion factor instead of the one developed from discret measurements should reduce part of the large discrepancy observed in Claustre et al. (2008) between Gross Community Production rates measured from an optical approach and estimated from standard measurements. Moreover, the relative low overestimation made in this study by the optically derived GCP is also related to the correction performed on the ${ }^{14} \mathrm{C}$ GPP production estimates being important to allow a direct comparison between the different approaches.

\section{Concluding remarks}

The three long duration stations located in the center of anticyclonic gyres, which have been sampled during the strongest stratified period, do not exhibit significant differences in terms of bio-optical environments. The surface TChl- $a$ values measured at these LD stations, with a mean value of $0.041 \pm 0.006 \mathrm{mg} \mathrm{m}^{-3}$, do not reflect the permanent trophic gradient existing from the western to the eastern basins of the Mediterranean Sea (Fig. 1). These stations are also peculiar from an optical point of view. Indeed, the surface specific phytoplankton absorption coefficients, $a_{\mathrm{phy}}{ }^{*}$, are similar for each LD station, but significantly lower than the values computed from mean (i.e. global) relationships. Such relatively low $a_{\text {phy }}$ * values are coherent with a significant contribution of nanophytoplankton to the total phytoplankton biomass, as highlighted by the relatively high size index and low non photosynthetic pigments to TChl- $a$ ratio found in these ecosystems. Absorption by non-algal particles contributes to about $40 \%$ of the particulate absorption measured at $440 \mathrm{~nm}$ in surface waters of the LD stations and does not exhibit any diurnal variations. Contrarily to the particulate absorption coefficients, the particulate scattering coefficient, and especially the particulate backscattering coefficient, present higher than mean (global) values for a given TChl- $a$ load. Highly refractive submicrometer particles from Saharan origin, exhibiting a negligible sinking velocity, could explain this particulate backscattering anomaly. This assumption is partly confirmed by a relatively high concentration of lithogenic silica, a desert dust tracer, in the surface waters sampled. Most of the observed blue-to-green reflectance ratio anomaly might therefore be explained by these high $b_{\mathrm{bp}}$ values with likely spectral dependency in the blue and green part of the spectrum. To a lesser extent it can also be attributed to a slightly greater absorption by colored non-algal particles and dissolved matter than the averaged (global) values. Further experiments, and especially spectral $b_{\mathrm{bp}}(\lambda)$ measurements over the whole visible spectrum, should however be performed to fully confirm these assumptions.

The diel cycle of the particulate backscattering coefficient observed from field measurements is reported for the very first time. Differences have been noticed between the diel cycles of $c_{\mathrm{p}}$ and $b_{\mathrm{bp}}$ measured at the long duration stations, such as the time shift between the $c_{\mathrm{p}}$ and $b_{\mathrm{bp}}$ maxima. However, the derived time series are not sufficiently long for providing any clear evidence allowing to explain the discrepancies existing between $b_{\mathrm{bp}}$ and $c_{\mathrm{p}}$ diel variations. Similarly, the origin of the differences observed within the gross community production rate estimated from the diel cycles of $c_{\mathrm{p}}$ or $b_{\mathrm{bp}}$, the latter being much closer to the estimated values by standard biogeochemical measurements, will have to be assessed. For that purpose the origin of the particle backscattering variability, which is still an open debate in the marine optics community, should be better characterized.

Acknowledgements. This is a contribution of the BOUM (Biogeochemistry from the Oligotrophic to the Ultraoligotrophic Mediterranean) experiment of the French national LEFE-CYBER program, the european IP SESAME and the international IMBER project. This work was also supported by the French spatial agency (CNES) in the frame of the TOSCA program. The authors also thank the crew of the R/V L'Atalante for outstanding shipboard operation. K. Oubelkheir is also thanked for providing the PROSOPE ac-9 data. Fruitful discussions with H. Claustre, and A. Bricaud were greatly appreciated. W. Gardner and an anonymous reviewer are acknowledged for their relevant comments and suggestions on the manuscript.

\section{Edited by: C. Jeanthon}

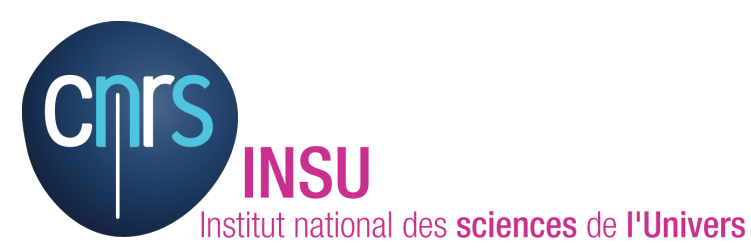

The publication of this article is financed by CNRS-INSU. 


\section{References}

Antoine, D., Chami, M., Claustre, H., D’Ortenzio, F., Morel, A., Bécu, G., Gentili, B., Louis, F., Ras, J., Roussier, E., Scott, A. J., Tailliez, D., Hooker, S. B., Guevel, P., Desté, J.-F., Dempsey, C., and Adams, D.: BOUSSOLE: a joint CNRS-INSU, ESA, CNES and NASA Ocean Color Calibration And Validation Activity, NASA Technical memorandum Nr. 214147, 61 pp., 2006.

Antoine, D., Siegel, D. A., Kostadinov, T., Maritorena, S., Nelson, N. B., Gentili, B., Vellucci, V., and Guillocheau, N.: Variability in optical particle backscattering in three contrasting bio-optical oceanic regimes, Limnol. Oceanogr., 56, 955-973, 2011.

Betzer, P. R., Carder, K. L., Duce, R. A., Merrill, J. T., Tindale, N. W., Uematsu, M., Costello, D. K., Young, R. W., Feely, R. A., Breland, J. A., Bernstein, R. E., and Greco, A. M.: Longrange transport of giant mineral aerosol particles, Nature, 336, 131-134, 1998.

Binder, B. J. and DuRand, M. D.: Diel cycles in surface waters of the Equatorial Pacific, Deep-Sea Res. Pt. II, 49, 2601-2617, 2002.

Bishop, J. K. B., Calvert, S. E., and Soon, M.: Spatial and temporal variability of POC in the northeast Subarctic Pacific, Deep-Sea Res. Pt. II, 46, 2699-2733, 1999.

Boss, E., Twardowski, M. S., and Herring, S.: Shape of the particulate beam attenuation spectrum and its inversion to obtain the shape of the particulate size distribution, Appl. Opt., 40, 48854893, 2001.

Boss, E., Pegau, W. S., Lee, M., Twardowskim, M. S., Shybanov, E., Korotaev, G., and Baratange, F.: Particulate backscattering ratio at LEO 15 and its use to study particles composition and distribution, J. Geophys. Res., 109, 1-10, doi:C0101410.1029/2002JC001514, 2004.

Boss, E., Collier, R., Larson, G., Fennel, K., and Pegau, W.: Measurements of spectral optical properties and their relation to biogeochemical variables and processes in Crater Lake, Crater Lake National Park, OR. Hydrobiol., 574, 1, 149-159, 2007.

Bricaud, A. and Morel, A.: Light attenuation and scattering by phytoplanktonic cells: a theoretical modeling, Appli. Opt., 25, 571580, 1986.

Bricaud, A. and Stramski D.: Spectral absorption coefficients of living phytoplankton and nonalgal biogenous matter: A comparison between the Peru upwelling area and the Sargasso Sea, Limnol. Oceanogr., 35 , 562-582, 1990.

Bricaud, A., Babin, M., Morel, A., and Claustre, H.: Variability in the chlorophyll-specific absorption coefficient of natural phytoplankton : analysis and parametrization, J. Geophys. Res., 100, C7, 13321-13332, 1995.

Bricaud, A., Morel, A., Babin, M., Allali, K., and Claustre, H.: Variations of light absorption by suspended particles with the chlorophyll a concentration in oceanic (Case 1) waters: analysis and implications for bio-optical models, J. Geophys. Res., 103, 31033-31044, 1998.

Bricaud, A., Bosc, E., and Antoine, D.: Algal biomass and sea surface temperature in the Mediterranean basin: intercomparison of data from various satellite sensors, and implications for primary production estimates, Rem. Sens. Environ., 81, 163-178, 2002.

Bricaud, A., Claustre, H., Ras, J., and Oubelkheir, K.: Natural variability of phytoplankton absorption in oceanic waters: influence of the size structure of algal populations, J. Geophys. Res., 109, C11010, doi:10.1029/2004JC002419, 2004.
Bricaud, A., Babin, M., Claustre, H., Ras, J., and Tieche, F.: Light absorption properties and absorption budget of South East Pacific waters, J. Geophys. Res., 115, C08009, doi:10.1029/2009JC005517, 2010.

Brown, C. A., Huot, Y., Werdell, P. J., Gentili, B., and Claustre, H.: The origin and global distribution of second order variability in satellite ocean color and its potential applications to algorithm development, Remote Sens. Environ., 112, 4186-4203, doi:10.1016/j.rse.2008.06.008, 2008.

Claustre, H.: The trophic status of various oceanic provinces as revealed by phytoplankton pigment signatures, Limnol. Oceanogr., 39, 5, 1206-1210, 1994.

Claustre, H., Morel, A., Babin, M., Cailliau, C., Marie, D., Marty, J.-C., and Vaulot, D.: Variability in particle attenuation and stimulated fluorescence in the tropical and equatorial Pacific: scales, patterns and some biogeochemical implications, J. Geophys. Res., 104, 3401-3422, 1999.

Claustre, H., Fell, F., Oubelkheir, K., Prieur, L., Sciandra, A., Gentili, B., and Babin, M.: Continuous monitoring of surface optical properties across a geostrophic front: biogeochemical inferences, Limnol. Oceanogr., 45, 309-321, 2000.

Claustre, H., Morel, A., Hooker, S. B., Babin, M., Antoine, D., Oubelkheir, K., Bricaud, A., Leblanc, K., Quéguiner, B., and Maritorena, S.: Is desert dust making oligotrophic waters greener? Geophys. Res. Lett., 29, 1469, doi:10.1029/2001GL014056, 2002.

Claustre, H., Huot, Y., Obernosterer, I., Gentili, B., Tailliez, D., and Lewis, M.: Gross community production and metabolic balance in the South Pacific Gyre, using a non intrusive biooptical method, Biogeosciences, 5, 463-474, doi:10.5194/bg-5463-2008, 2008.

Cullen, J. J.: The deep chlorophyll maximum: Comparing vertical profiles of chlorophyll- $a$, Can. J. Fish. Aquat. Sci., 39; 791-803, 1982.

Cullen, J. J., Lewis, M., Davis, C. O., and Barber, R.: Photosynthetic characteristics and estimated growth rates indicate grazing is the proximate control of primary production in the Equatorial Pacific, J. Geophys. Res., 97; 639-655, doi:10.1029/91JC01320, 1992.

Dall'Olmo, G., Westberry, T. K., Behrenfeld, M. J., Boss, E., and Slade, W. H.: Significant contribution of large particles to optical backscattering in the open ocean, Biogeosciences, 6, 947-967, doi:10.5194/bg-6-947-2009, 2009.

Dall'Olmo, G., Westberry, T. K., Behrenfeld, M. J., Boss, E., Courties, C., Prieur, L., Hardman-Mountford, N., and Moutin, T.: Inferring phytoplankton carbon and eco-physiological rates from diel cycles of spectral particulate beam-attenuation coefficient, Biogeosciences Discuss., 8, 3009-3050, doi:10.5194/bgd8-3009-2011, 2011.

D’Ortenzio F., Marullo, S., Ragni, M., Ribera D'Alcalà, M., and Santoleri R.: Validation of empirical SeaWiFS algorithms for chlorophyll- $a$ retrieval in the Mediterranean Sea: a case study for oligotrophic seas, Rem. Sens. Envir., 82, 79-94, 2002.

Duforêt-Gaurier, L., Loisel, H., Dessailly, D., Nordkvist, K., and Alvain, S.: Estimates of particulate organic carbon over the euphotic depth from in situ measurements, Application to satellite data over the global ocean, Deep Sea Res. Pt. I, 57, 351-367, 2010.

Dupouy, C., Loisel, H., Neveux, J., Moulin, C., Brown, S., Blan- 
chot, J., Lebouteiller, A., and Landry, M.: Microbial absorption and backscattering coefficients from in situ and POLDER satellite during an El Nino-Southern Oscillation cold phase in the equatorial Pacific $\left(180^{\circ}\right)$, J. Geophys. Res., 108, 8138, 1-14, 2003

Durand, M. D. and Olson, R. J.: Contributions of phytoplankton light scattering and cell concentration changes to diel variations in beam attenuation in the Equatorial Pacific from flow cytometric measurements of pico-, ultra- and nanoplankton, Deep-Sea Res. Pt. II, 43, 891-906, 1996.

Durand, M. D. and Olson, R. J.: Diel patterns in optical properties of the chlorophyte Nannochloris sp.: relating individual-cell to bulk measurements, Limnol. Oceanogr., 43, 1107-1118, 1998.

Gardner, W. D., Chung, S. P., Richardson, M. J., and Walsh, I. D.: The oceanic mixed-layer pump, Deep-Sea Res., 42, 757-775, 1995.

Gardner, W. D., Gundersen, J. S., Richardson, M. J., and Walsh, I. D.: The role of seasonal and diel changes in mixed-layer depth on carbon and chlorophyll distributions in the Arabian Sea, DeepSea Res. Pt. II, 46, 1833-1858, 1999.

Gardner, W. D., Richardson, M. J., and Smith, W. O.: Seasonal patterns of water column particulate organic carbon and fluxes in the Ross Sea Antarctica, Deep Sea Res. Pt. II, 47, 3423-3449, 2000.

Gardner, W. D., Mishonov, A. V., and Richardson, M. J.: Global POC concentrations from in-situ and satellite data, Deep-Sea Res. Pt. II, 53, 718-740, 2006.

Gernez, P. D., Antoine D., and Huot, Y.: Diel cycles of the particulate beam attenuation coefficient under varying trophic conditions in the northwestern Mediterranean Sea: observations and modeling, Limnol. Oceanogr., 56, 17-36, 2011.

Gitelson, A., Karnieli, A., Goldman, N., Yacobi, Y. Z., and Mayo, M.: Chlorophyll estimation in the Southeastern Mediterranean using CZCS images: adaptation of an algorithm and its validation, J. Mar. Syst., 9, 283-290, 1996.

Gordon, H. R. and Morel, A.: Remote assessment of ocean color for interpretation of satellite visible imagery. A review, SpringerVerlag, New York (USA), 1983.

Grob, C., Ulloa, O., Claustre, H., Huot, Y., Alaren, G., and Marie, D.: Contribution of picoplankton to the total particulate organic carbon concentration in the eastern South Pacific, Biogeosciences, 4, 837-852, doi:10.5194/bg-4-837-2007, 2007.

Huot, Y., Morel, A., Twardowski, M. S., Stramski, D., and Reynolds, R. A.: Particle optical backscattering along a chlorophyll gradient in the upper layer of the eastern South Pacific Ocean, Biogeosciences, 5, 495-507, doi:10.5194/bg-5-4952008, 2008.

IOCCG, Remote Sensing of Inherent Optical Properties: Fundamentals, Tests of Algorithms, and Applications, in Reports of the International Ocean-Colour Coordinating Group, No. 5, edited by: Lee, Z. P., IOCCG, Dartmouth, 2006.

Karageorgis, A. P., Gardner, W. D., Georgopoulos, D., Mishonov, A. V., Krasakopoulou, E., and Anagnostou, C.: Particle dynamics in the Eastern Mediterranean Sea: A synthesis based on light transmission, PMC, and POC archives (1991-2001), Deep-Sea Res. Pt. I, 55, 2, 177-202, 2008.

Kiefer, D. A., Olson, R. J., and M-Hansen, H.: Another look at the nitrite and chlorophyll maxima in the central north Pacific, Deep-Sea Res., 23, 1199-1208, 1976.
Kitchen J. C. and Zaneveld, J. R. V.: On the noncorrelation of the vertical structure of light scattering and chlorophyll a in case I waters, J. Geophys. Res., 95, 20237-20246, 1990.

Letelier, R. M., Karl, D. M., Abbott, M. R., and Bidigare, R. R.: Light driven seasonal patterns of chlorophyll and nitrate in the lower euphotic zone of the North Pacific Subtropical Gyre, Limnol. Oceanogr., 49, 508-519, 2004.

Loisel, H. and Morel, A.: Light scattering and chlorophyll concentration in case 1 waters: a re-examination, Limnol. Oceanogr., 43, 847-857, 1998.

Loisel, H. and Stramski, D.: Estimation of the inherent optical properties of natural waters from irradiance attenuation coefficient and reflectance in the presence of Raman scattering, Appl. Opt., 39, 3001-3011, 2000.

Loisel, H., Bosc, E., Stramski, D., Oubelkheir, K., and Deschamps, P. Y.: Seasonal variability of the backscattering coefficients in the Mediterranean Sea based on Satellite SeaWIFS imagery, Geophys. Res. Lett., 28, 4203-4206, 2001.

Loisel, H., Nicolas, J. M., Sciandra, A., Stramski, D., and Poteau, A.: Spectral dependency of optical backscattering by marine particles from satellite remote sensing of the global ocean, J. Geophys. Res., 111, C09024, doi:10.1029/2005JC003367, 2006.

Loisel, H., Mériaux, X., Berthon, J. F., and Poteau, A. : Investigation of the optical backscattering to scattering ratio of marine particles in relation to their biogeochemical composition in the eastern English Channel and southern North Sea, Limnol. Oceanogr., 52, 739-752, 2007.

Loisel, H., Lubac, B., Dessailly, D., Duforêt-Gaurier, L., and Vantrepotte, V.: Effect of inherent optical properties variability on the chlorophyll retrieval from ocean color remote sensing: an in situ approach, Opt. Expr., 18, 20, 20949-20959, 2010.

Lubac, B. and Loisel, H.: Variability and classification of remote sensing reflectance spectra in the Eastern English Channel and southern North Sea, Rem. Sens. Environ., 110, 45-58, 2007.

Marra, J., Langdon, C., and Knudson, C. A.: Primary production, water column changes, and the demise of Phaeocystis bloom at the Marine Light-Mixed Layers site $\left(59^{\circ} \mathrm{N}, 21^{\circ} \mathrm{W}\right)$ in the northeast Atlantic Ocean, J. Geophys. Res., 100, 6633-6643, 1995.

Marty, J. C., Chiaverini, J., Pizay, M. D., and Avril, B.: Seasonal and interannual dynamics of nutrients and phytoplankton pigments in the western Mediterranean Sea at the DYFAMED timeseries station (1991-1999), Deep-Sea Res. Pt. II, 49, 1965-1985, 2002.

Mitchell, B. G., Kahru, M., Wieland, J., and Stramska, M.: Ocean Optics Protocol for Satellite Ocean Color Sensor Validation, Volume IV: Chapter 4: A Determination of Spectral Absorption Coefficients of Particles, dissolved material and phytoplankton for discrete water sample, NASA, TM-2003., 2003

Morel, A.:. Optical modeling of the upper ocean in relation to its biogenous matter content (case 1 water), J. Geophys. Res., 93, 10749-10768, 1988.

Morel, A.: Are the empirical relationships describing the bio-optical properties of case 1 waters consistent and internally compatible?, J. Geophys. Res., 114, C01016, doi:10.1029/2008JC004803, 2009.

Morel, A. and Bricaud, A.: Theoretical results concerning light absorption in a discrete medium, and application to specific absorption of phytoplankton, Deep-Sea Res., 28, 1375-1393, 1981.

Morel, A. and Bricaud, A.: Inherent optical properties of algal 
cells, including picoplankton. Theoretical and experimental results, Can. Bull. Fish. Aquat. Sc., 214, 521-559, 1986.

Morel, A. and Ahn, Y. H.: Optics of heterotrophic nanoflagellates and ciliates: A tentative assessment of their scattering role in oceanic waters compared to those of bacterial and algal cells, J. Mar. Res., 49, 177-202, 1991.

Morel, A. and Maritorena, S.: Bio-optical properties of oceanic waters: A reappraisal, J. Geophys. Res., 106, 7763-7780, 2001.

Morel, A. and Gentili, B.: The dissolved yellow substance and the shades of blue in the Mediterranean Sea, Biogeosciences, 6, 2625-2636, doi:10.5194/bg-6-2625-2009, 2009.

Morel, A., Claustre, H., Antoine, D., and Gentili, B.: Natural variability of bio-optical properties in Case 1 waters: attenuation and reflectance within the visible and near-UV spectral domains, as observed in South Pacific and Mediterranean waters, Biogeosciences, 4, 913-925, doi:10.5194/bg-4-913-2007, 2007.

Moutin, T. and Raimbault, P.: Primary production, carbon export and nutrients availability in western and eastern Mediterranean Sea in early summer 1996, MATER Special Issue, J. Mar. Syst., 33/34, 273-288, 2002.

Moutin, T., Raimbault, P., and Poggiale, J. C.: Production primaire dans les eaux de surface de la Méditerranée occidentale: Calcul de la production journalière, C. R. Acad. Sci. Paris, Sciences de la vie, 322, 651-659, 1999.

Moutin, T., Van Wambeke, F., and Prieur, L.: The Biogeochemistry from the Oligotrophic to the Ultraoligotrophic Mediterranean (BOUM) experiment, Biogeosciences Discuss., 8, 8091-8160, doi:10.5194/bgd-8-8091-2011, 2011.

Mueller, J. L.: In-water radiometric profile measurements and data analysis protocols, NASA/TM, 211621/Rev4-vol3, 7-20, 2003.

Nelson, D. M., Smith Jr., W. O., Muench, R. D., Gordon, L. I., Sullivan, C. W., and Husby, D. M.: Particulate matter and nutrient distribution in the ice edge zone of the Weddell Sea: relationship to hydrography during late summer, Deep-Sea Res., 36, 191209, 1989.

Nelson, N. B., Siegel, D. A., and Michaels, A. F.: Seasonal dynamics of colored dissolved material in the Sargasso Sea, Deep-Sea Res., 45, 931-957, 1998.

O'Reilly, J. E., Maritorena, S., Mitchell, B. G., Siegel, D. A., Carder, K. L., Garver, S. A., Kahru, M., and McClain, C. R.: Ocean color chlorophyll algorithms for SeaWiFS, J. Geophys. Res., 103, 24937-24953, 1998.

Oubelkheir, K. and Sciandra, A.: Diel variations in particle stocks in the oligotrophic waters of the Ionian Sea (Mediterranean), J. Mar. Syst., 74, 364-371, 2008.

Oubelkheir, K., Claustre, H., Babin, M., and Sciandra, A.: The comparative bio-optical and biogeochemical properties of contrasted trophic regimes, Limnol. Oceanogr., 50, 1795-1809, 2005.

Oubelkheir, K., Claustre, H., Bricaud, A., and Babin, M.: Partitioning total spectral absorption in phytoplankton and colored detrital material contributions, Limnol. Oceanogr. Meth., 5, 384-395, 2007.

Pak, H., Kiefer, D. A., and Kitchen, J. C.: Meridional variations in the concentration of chlorophyll and microparticlesin the North Pacific Ocean, Deep-Sea Res., 35, 1151-1171, 1988.

Pope, R. M. and Fry, E. S.: Absorption spectrum (380-700 nm) of pure water, II., Integrating cavity measurements, Appl. Opt., 36, 8710-8723, 1997.
Ragueneau, O. and Tréguer, P.: Determination of biogenic silica in coastal waters: applicability and limits of the alkaline digestion method, Mar. Chem., 45, 43-51, 1994.

Ragueneau, O., Savoye, N., Del Amo, Y., Cotten, J., Tardiveau, B., and Leynaert, A.: A new method for the measurement of biogenic silica in suspended matter of coastal waters: using Si:Al ratios to correct for the mineral interference, Cont. Shelf Res., 25, 697-710, 2005.

Ras, J., Claustre, H., and Uitz, J.: Spatial variability of phytoplankton pigment distributions in the Subtropical South Pacific Ocean: comparison between in situ and predicted data, Biogeosciences, 5, 353-369, doi:10.5194/bg-5-353-2008, 2008.

Reynolds, R. A., Stramski, D., and Mitchell, B. G.: A chlorophylldependent semi analytical model derived from field measurements of absorption and backscattering coefficients within the Southern Ocean, J. Geophys. Res., 106, 7125-7138, 2001.

Roesler, C. S. and Boss, E.: In situ measurement of the inherent optical properties (IOPs) and potential for harmful algal bloom (HAB) detection and coastal ecosystem observations, Chapter 5, 153-206, in: Babin, edited by: Roesler, M., Collin, S., Cullen, J., Real-time Coastal Observing Systems for Marine Ecosystem Dynamics and Harmful Algal Blooms: Theory, Instrumentation and Modelling, Paris: UNESCO, 2008.

Siegel, D. A., Dickey, D. A., Washburn, L., Hamilton, M. K., and Mitchell, B. G.: Optical determination of particulate abundance and production variations in the oligotrophic ocean, Deep-Sea Res., 36, 211-222, 1989.

Slade, W. H., Boss, E., Dall'Olmo, G., Langner, M. R., Loftin, J., Behrenfeld, M. J., Roesler, C., and Westberry, T. K.: Underway and moored methods for improving accuracy in measurement of spectral particulate absorption and attenuation, J. Atm. Ocean. Tech., 27, 1733-1746, doi:10.1175/2010JTECHO755.1, 2010.

Smith, R. C. and Baker, K. S.: The bio-optical state of ocean waters and remote sensing, Limnol. Oceanogr., 23, 247-259, 1978.

Stramska, M. and Stramski, D.: Variability of particulate organic carbon concentration in the north polar Atlantic on SeaWiFS ocean color observation, J. Geophys. Res., 110, C10018, 2005.

Stramski, D.: Refractive index of planktonic cells as a measure of cellular carbon and chlorophyll a content, Deep-Sea Res., 46, 335-351, 1999.

Stramski, D. and Kiefer, D. A.: Light scattering by microorganisms in the open ocean, Progr. Oceanogr., 28, 343-383, 1991.

Stramski, D. and Reynolds, R. A.: Diel variations in the optical properties of a marine diatom, Limnol. Oceanogr., 38, 13471364, 1993.

Stramski, D., Reynolds, R. A., Kahru, M., and Mitchell, B. G.: Estimation of particulate organic carbon in the ocean from satellite remote sensing, Science, 285, 239-241, 1999.

Stramski, D., Boss, E., Bogucki, D., and Voss, K. J.: The role of seawater constituents in light backscattering in the ocean, Prog. Oceanogr., 61, 27-56, 2004.

Sullivan, J. M., Twardowski, M. S., Donaghay, P. L., and Freeman, S. A.: Use of optical scattering to discriminate particle types in coastal waters, Appl. Opt., 44, 1667-1680, 2005.

Ternon, E., Guieu, C., Ridame, C., L'Helguen, S., and Catala, P.: Longitudinal variability of the biogeochemical role of Mediterranean aerosols in the Mediterranean Sea, Biogeosciences, 8, 1067-1080, doi:10.5194/bg-8-1067-2011, 2011.

Twardowski, M. S., Boss, E., Macdonald, J. B., Pegau, W. S., 
Barnard, A. H., and Zaneveld, J. R. V.: A model for estimating bulk refractive index from the optical backscattering ratio and the implications for understanding particle composition in Case I and Case II waters, J. Geophys. Res., 106, 14129-14142, 2001.

Twardowski, M. S., Claustre, H., Freeman, S. A., Stramski, D., and Huot, Y.: Optical backscattering properties of the "clearest" natural waters, Biogeosciences, 4, 1041-1058, doi:10.5194/bg-41041-2007, 2007.

Uitz, J., Claustre, H., Morel, A., and Hooker, S.: Vertical distribution of phytoplankton communities in open ocean: an assessment based on surface chlorophyll, J. Geophys. Res., 111, C08005, doi:10.1029/2005JC003207, 2006.

Ulloha, O., Sathyendranath, S., and Platt, T.: Effect of the particlesize distribution on the backscattering ratio in seawater, Appl. Opt., 33, 7070-7077, 1994.

Vaillancourt, R. D., Brown, C. W., Guillard, R. R. L., and Balch, W. M.: Light backscattering properties of marine phytoplankton: relationships to cell size, chemical composition and taxonomy, J. Plank. Research, 26, 191-212, 2004.
Vantrepotte, V., Loisel, H., Mélin, F., Dessailly, D., and DuforêtGaurier, L. : Global particulate matter pool temporal variability over the SeaWiFS period (1997-2007), Geophys. Res., Let., 38, L02605, doi:10.1029/2010GL046167, 2011.

Vaulot, D. and Marie, D.: Diel variability of photosynthetic picoplankton in the Equatorial Pacific, J. Geophys. Res., 104, 3297-3310, 1999.

Vidussi, F., Claustre, H., Manca, B., Luchetta, A., and Marty, J.C.: Phytoplankton pigment distribution in relation to the upper thermocline circulation in the Eastern Mediterranean Sea during winter, J. Geophys. Res., 106, 19939-19956, 2001.

Walsh, I. D., Chung, S. P., Richardson, M. J., and Gardner, W. D.: The diel cycle in the Integrated Particle Load in the Equatorial Pacific: A Comparison with Primary Production, Deep-Sea Res. Pt. II, 42, 465-477, 1995.

Yentsch, C. S. and Phinney, D. A.: A bridge between ocean optics and microbial ecology, Limnol. Oceanogr., 34, 1694-1705, 1989.

Zhang, X., Hu, L., and He, M.-X.: Scattering by pure seawater: effect of salinity, Opt. Express, 17, 5698-5710, 2009. 